\title{
An aircraft-borne chemical ionization - ion trap mass spectrometer (CI-ITMS) for fast PAN and PPN measurements
}

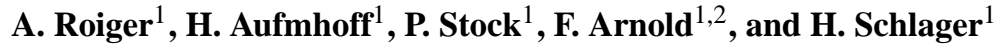 \\ ${ }^{1}$ Deutsches Zentrum für Luft- und Raumfahrt (DLR), Institut für Physik der Atmosphäre, Oberpfaffenhofen, Germany \\ ${ }^{2}$ Max-Planck-Institute for Nuclear Physics (MPIK), Atmospheric Physics Division, Heidelberg, Germany
}

Received: 21 August 2010 - Published in Atmos. Meas. Tech. Discuss.: 5 October 2010

Revised: 24 January 2011 - Accepted: 25 January 2011 - Published: 4 February 2011

\begin{abstract}
An airborne chemical ionization ion trap mass spectrometer instrument (CI-ITMS) has been developed for tropospheric and stratospheric fast in-situ measurements of PAN (peroxyacetyl nitrate) and PPN (peroxypropionyl nitrate). The first scientific deployment of the FASTPEX instrument (FASTPEX = Fast Measurement of Peroxyacyl nitrates) took place in the Arctic during 18 missions aboard the DLR research aircraft Falcon, within the framework of the POLARCAT-GRACE campaign in the summer of 2008. The FASTPEX instrument is described and characteristic properties of the employed ion trap mass spectrometer are discussed. Atmospheric data obtained at altitudes of up to $\sim 12 \mathrm{~km}$ are presented, from the boundary layer to the lowermost stratosphere. Data were sampled with a time resolution of $2 \mathrm{~s}$ and a $2 \sigma$ detection limit of $25 \mathrm{pmol} \mathrm{mol}^{-1}$. An isotopically labelled standard was used for a permanent on-line calibration. For this reason the accuracy of the PAN measurements is better than $\pm 10 \%$ for mixing ratios greater than $200 \mathrm{pmol} \mathrm{mol}^{-1}$. PAN mixing ratios in the summer Arctic troposphere were in the order of a few hundred $\mathrm{pmol} \mathrm{mol}^{-1}$ and generally correlated well with CO. In the Arctic boundary layer and lowermost stratosphere smaller PAN mixing ratios were observed due to a combination of missing local sources of PAN precursor gases and efficient removal processes (thermolysis/photolysis). PPN, the second most abundant PAN homologue, was measured simultaneously. Observed PPN/PAN ratios range between $\sim 0.03$ and 0.3 .
\end{abstract}

\section{Introduction}

Peroxyacetyl nitrate (PAN, $\mathrm{CH}_{3} \mathrm{C}(\mathrm{O}) \mathrm{O}_{2} \mathrm{NO}_{2}$ ) is one of the main compounds of the reactive nitrogen family $\mathrm{NO}_{\mathrm{y}}\left(\mathrm{NO}_{\mathrm{y}}=\right.$ $\left.\mathrm{NO}, \mathrm{NO}_{2}, \mathrm{HNO}_{3}, \mathrm{PAN}, \mathrm{N}_{2} \mathrm{O}_{5}, \mathrm{NO}_{3}, \ldots\right)$. As a major tempo-

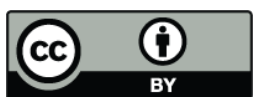

Correspondence to: A. Roiger

(anke.roiger@dlr.de) rary $\mathrm{NO}_{\mathrm{x}}$ reservoir gas, PAN plays an important role in tropospheric ozone chemistry. It was originally discovered as a major component of the Los Angeles smog (Haagen-Smit, 1952) and was first identified in the laboratory by Stephens et al. (1956). Atmospheric mixing ratios range from a few pmol mol ${ }^{-1}$ in remote regions to several $\mathrm{nmol} \mathrm{mol}^{-1}$ in smog situations, where PAN may cause eye-irritations and plant damage (Altshuller, 1993).

PAN is not emitted directly into the atmosphere but represents a common intermediate in the atmospheric degradation of various volatile organic compounds (VOC). In the presence of nitrogen oxides, the peroxyacetyl (PA) radical finally reacts with $\mathrm{NO}_{2}$ leading to PAN:

$\mathrm{CH}_{3} \mathrm{C}(\mathrm{O}) \mathrm{O}_{2}+\mathrm{NO}_{2} \leftrightarrows \mathrm{CH}_{3} \mathrm{C}(\mathrm{O}) \mathrm{O}_{2} \mathrm{NO}_{2}$

PAN is thermally very labile and may decompose, thereby releasing $\mathrm{NO}_{2}$ and the PA radical. The PAN lifetime against thermal decomposition in the boundary layer is typically less than one hour, whereas in the colder upper troposphere PAN may survive for several weeks to months (Talukdar et al., 1995).

Also a series of higher PAN homologues, e.g. PPN (peroxypropionyl nitrate, $\mathrm{CH}_{3} \mathrm{CH}_{2} \mathrm{C}(\mathrm{O}) \mathrm{O}_{2} \mathrm{NO}_{2}$ ) and MPAN (peroxymethacryloyl nitrate, $\left.\mathrm{CH}_{3} \mathrm{CCH}_{2} \mathrm{C}(\mathrm{O}) \mathrm{O}_{2} \mathrm{NO}_{2}\right)$, have been observed in the atmosphere, often at mixing ratios of roughly an order of magnitude lower than that of PAN (Roberts et al., 2004, 2007; Wolfe et al., 2007; LaFranchi et al., 2009). These homologues are formed through similar chemistry, but have different parent VOCs. Hence, the measured relative abundances of different PANs can be used as indicators for the precursor VOCs (Williams et al., 1997; Roberts et al., 2002).

The best established technique for measurements of PAN and its homologues is gas chromatography with an electron capture detector (GC-ECD), which benefits from good characterisation and provides low detection limits of a few pmol mol $^{-1}$ (Singh and Salas, 1983; Williams et al., 2000;

Published by Copernicus Publications on behalf of the European Geosciences Union. 
Flocke et al., 2005b). However, the time resolution in the range of several minutes is low, especially for airborne measurements, where time resolution is equivalent to spatial resolution. Meanwhile, also the CIMS technique (Chemical Ionization Mass Spectrometry) is employed for the measurement of PAN. CIMS techniques provide generally a high time resolution $(\sim 1 \mathrm{~s})$ in combination with low detection limits in the range of a few $\mathrm{pmol} \mathrm{mol}^{-1}$. CIMS was originally introduced in atmospheric research by Arnold et al. (1978) and now is established as a powerful method for the measurement of a series of trace gases (Kiendler et al., 2000; Neuman et al., 2000; Nowak et al., 2002; Thornton et al., 2002; Hanke et al., 2003; Slusher et al., 2004; Speidel et al., 2007; Kercher et al., 2009), for a recent review see for example Huey (2007).

CIMS is based on the selective ionization of the desired trace gas in the sample air followed by detection of precursor and characteristic product ions inside the mass spectrometer. Apart from its high time resolution and low detection limit, the CIMS technique offers high versatility: it provides the possibility of measuring a series of different trace gases if used with different precursor ions.

However, the accuracy of CIMS-systems might be influenced by various parameters. The major uncertainty is due to the uncertainty of the rate constants of the ion-molecule reactions used. In particular ambient water vapour variations may cause problems, because the rate constants are somewhat dependent on the number of water molecules attached to the ions participating in the reaction scheme. Wall losses or memory effects, especially of sticky molecules, might also differ with varying humidity. Furthermore, ion transmission or detector fluctuations of the mass spectrometer can result in sensitivity variations. For these reasons, in-flight calibrations are essential in order to carry out measurements with high accuracy. The most elegant way to control all aspects mentioned is to use an isotopically labelled standard for an on-line calibration throughout the entire flight.

For airborne PAN measurements, two different CIMS methods have been used in recent years, Proton Transfer Mass Spectrometry (PTR-MS) using protonated PAN as product ion (Holzinger et al., 2005), and a thermal dissociation (TD-CIMS) technique using $\mathrm{I}^{-}$as reagent ions (Slusher et al., 2004). Whereas the PTR-MS technique might suffer from an interference from peroxyacetic acid (de Gouw et al., 2003), the use of the $\mathrm{I}^{-}$reagent ions has been established for both ground-based (Turnipseed et al., 2006; Wolfe et al., 2007; LaFranchi et al., 2009) and aircraft measurements (Flocke et al., 2005a; Neuman et al., 2006; Alvarado et al., 2010). All these measurements were performed using CIMS instruments equipped with a linear quadrupole mass spectrometer (LQMS).

In this paper, we present the first deployment of FASTPEX (Fast Measurement of Peroxyacyl nitrates), an airborne CIMS-instrument equipped with an ion trap mass spectrometer (CI-ITMS) using $\mathrm{I}^{-}$-chemistry for the measurement of PAN. Ion trap mass spectrometers offer certain advantages:
Ion traps have a large mass range $(\sim 15-2000 \mathrm{amu})$, a high sensitivity also at high mass to charge $(\mathrm{m} / \mathrm{z})$ ratios and an excellent duty cycle. The quasi-simultaneous sampling of all ions over the desired mass range is especially helpful if air masses with different atmospheric trace gas concentrations are rapidly intercepted by a research aircraft, as for example in aircraft exhaust plumes (Jurkat et al., 2011). A whole spectrum can be derived within $\mathrm{ms}$ if a high time resolution is needed. On the contrary, at low ion concentrations a higher sensitivity can be obtained by increasing the sampling time (Fiedler et al., 2005; Aufmhoff et al., 2011). A mass resolution of $\sim 0.3 \mathrm{amu}$ is achieved over the entire mass range which leads to an unambigous detection of neighbouring air masses. This is especially important if an isotopic calibration is used, as in the present study. The "calibration" peak is, dependent on the isotope used, generally one or two mass units apart from the "ambient" mass peak. Finally, an ITMS (ion trap mass spectrometer) allows the performance of fragmentation studies of mass selected ions, which may greatly improve ion identification. The ion fragmentation mode of an ITMS can be used in flight or in laboratory test measurements (Kiendler and Arnold, 2003; Schroeder et al., 2003).

FASTPEX was successfully deployed for the first time aboard the DLR research aircraft Falcon during the GRACE campaign (Greenland Aerosol and Chemistry Experiment), a sub-project of the POLARCAT initiative (Polar Study using Aircraft, Remote Sensing, Surface Measurements and Models, of Climate, Chemistry, Aerosols, and Transport - Greenland Aerosol and Chemistry Experiment). The GRACE campaign aimed to study the influence of both boreal forest fire and anthropogenic emissions on the summer-time Arctic chemistry of the troposphere and lowermost stratosphere. The Falcon was based at Kangerlussuaq (Greenland) in June 2008 and a total of 16 local research flights of up to $\sim 12 \mathrm{~km}$ altitude were performed. PAN measurements in particular are sparse in the Arctic summer-time troposphere. Singh et al. (1992) found increasing PAN mixing ratios with increasing altitude during measurements above Greenland in the summer of 1988, but their measurements were limited to an altitude of $\sim 6 \mathrm{~km}$.

The present paper starts with a detailed description of the FASTPEX instrument in Sect. 2. The results from optimization and cross-sensitivity tests in the laboratory are summarized in Sect. 3. In Sect. 4 we present some raw data from atmospheric measurements and discuss characteristic properties of the ion trap mass spectrometer, finally we show a few examples of atmospheric PAN and PPN measurements. A summary and outlook is given in Sect. 5.

\section{Experimental set-up}

Figure 1 shows a schematic representation of the FASTPEX instrument as employed during the POLARCATGRACE campaign. FASTPEX is composed of several major 


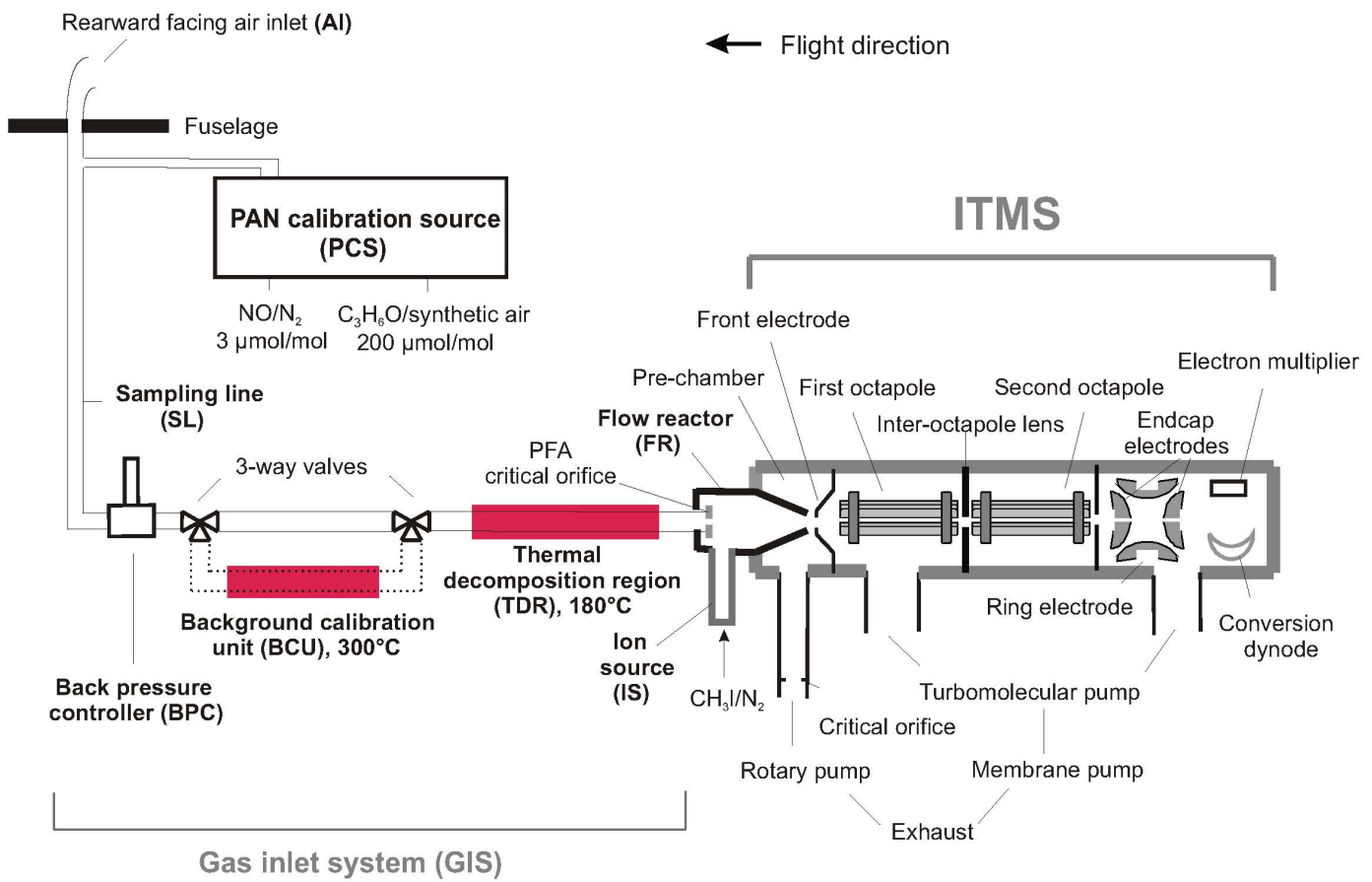

Fig. 1. Experimental set-up of the FASTPEX instrument as deployed on the DLR Falcon during the POLARCAT-GRACE campaign 2008. The main components of FASTPEX are a gas inlet system (GIS), a PAN calibration source (PCS), a tubular flow reactor (FR), an ion source (IS) and an ion trap mass spectrometer (ITMS). For more details see text.

components, a gas inlet system (GIS), a PAN calibration source (PCS), a tubular flow reactor (FR), an ion source (IS) and an ion trap mass spectrometer (ITMS).

FASTPEX is operated as follows: Atmospheric air is drawn in by a rotary vane pump through the backwardoriented air inlet (AI) sticking out of the aircraft top fuselage and the aircraft boundary layer. Thereupon the air passes through the sampling line (SL) via a back pressure controller (BPC) into the thermal decomposition region (TDR). Here, atmospheric PAN undergoes thermal decomposition leading to the formation of peroxyacetyl (PA) radicals $\mathrm{CH}_{3} \mathrm{C}(\mathrm{O}) \mathrm{O}_{2}$ and $\mathrm{NO}_{2}$. Subsequently the air enters the flow reactor (FR), where also reagent ions $\mathrm{I}^{-}$generated by the ion source (IS) are introduced. After passage through the FR, the air is pumped out by the rotary vane pump (Alcatel 9014) and exits the instrument via an air exhaust. A small fraction of the atmospheric air containing reagent and product ions enters the ITMS via a small circular entrance orifice (drilled into the front electrode) where it is analyzed.

Online calibration is carried out by using isotopically labelled PAN (containing ${ }^{13} \mathrm{C}$ atoms), which is generated by the PAN calibration source (PCS). For instrumental background measurements a hot $\mathrm{Au}$ tube (BCU) is integrated into the FASTPEX instrument in a bypass line of the SL. All temperatures as well as mass flow and pressure controllers/sensors (Wagner Mess- und Regeltechnik) are controlled by a custom-written "LabView" program. In the fol- lowing, the major components of and processes taking place in the FASTPEX instrument will be described in detail.

\subsection{Gas inlet system (GIS)}

The gas inlet system is used for the transfer of ambient air to the flow reactor and is composed of an air inlet (AI) and a sampling line SL (PFA, 3/8" OD) which contains a back-pressure controller (BPC), a background calibration unit (BCU) and a thermal decomposition region (TDR). The $\mathrm{AI}$ is a $90^{\circ}$ angled inlet oriented opposite to the direction of flight. During the flights it is permanently heated $\left(\sim 20^{\circ} \mathrm{C}\right)$ in order to avoid icing. The BPC regulates the pressure downstream in order to keep the pressure in the following sampling line constant $(150 \mathrm{hPa})$ and independent of the varying ambient pressure. The BPC warms up while in operation, and an increase in the temperature of the BPC may alter its transmission of PAN. For this reason we performed several tests in the laboratory but no thermal loss was observed: obviously the residence time of a few $\mathrm{ms}$ in the BPC is short enough.

The ion-molecule reaction with the reagent ions involves the thermal decomposition product of PAN, the PA radical $\left(\mathrm{CH}_{3} \mathrm{C}(\mathrm{O}) \mathrm{O}_{2}\right)$, which is generated by drawing the sample gas through the thermal decomposition region (heated PFA tube, $50 \mathrm{~cm}, 180^{\circ} \mathrm{C}$ ). The TDR is separated by a critical orifice (PFA, diameter $1.0 \mathrm{~mm}$ ) from the flow reactor $(\mathrm{FR})$. The 
background calibrations are performed by passing the sample gas regularly first through the BCU using a three-way valve system (in the following referred to as "BCU-mode"). In the $\mathrm{BCU}\left(30 \mathrm{~cm}, 300^{\circ} \mathrm{C}\right), \mathrm{PAN}$ is also thermally destroyed, but the PA radicals hereby generated are rapidly lost by surface catalysis and therefore do not reach the flow reactor.

\subsection{Ion source (IS) and flow reactor (FR)}

Immediately after the PFA orifice, the sampling gas is introduced into the tubular FR (stainless steel, $40 \mathrm{~mm}$ OD, $16 \mathrm{~cm}$ length) where it mixes with the reagent gas coming from the ion source. The reagent ions $\mathrm{I}^{-}$are produced by adding trace amounts of a $\mathrm{CH}_{3} \mathrm{I} / \mathrm{N}_{2}$ gas mixture $\left(1000 \mu \mathrm{mol} \mathrm{mol}^{-1} \mathrm{CH}_{3} \mathrm{I}\right.$ in $\mathrm{N}_{2}$ 5.0, Air Liquide) to the $\mathrm{N}_{2}$ carrier gas which passes through a radioactive ${ }^{210} \mathrm{Po}$ inline-ionizer $(20 \mathrm{mCu}$, NRD). Ion-molecule reactions take place along the whole length of the FR. The $\mathrm{I}^{-}$ions react very rapidly with atmospheric water vapour molecules, leading to hydrated $\mathrm{I}^{-}\left(\mathrm{H}_{2} \mathrm{O}\right)_{n}$ cluster ions. These serve as effective reagent ions for the detection of the PA-radicals formed in the TDR leading to product ions $\mathrm{CH}_{3} \mathrm{C}(\mathrm{O}) \mathrm{O}^{-}\left(\mathrm{H}_{2} \mathrm{O}\right)_{\mathrm{n}}\left(k=9_{-5}^{+7} \times 10^{-10} \mathrm{~cm}^{3}\right.$ molecule $^{-1} \mathrm{~s}^{-1}$ in $\mathrm{He}$ at $67 \mathrm{~Pa}$, Villalta and Howard, 1996).

$\mathrm{CH}_{3} \mathrm{C}(\mathrm{O}) \mathrm{O}_{2}+\mathrm{I}^{-}\left(\mathrm{H}_{2} \mathrm{O}\right)_{\mathrm{n}} \rightarrow \mathrm{CH}_{3} \mathrm{C}(\mathrm{O}) \mathrm{O}^{-}\left(\mathrm{H}_{2} \mathrm{O}\right)_{\mathrm{n}}+\mathrm{IO}$.

The product ions formed are distributed in several mass peaks due to the formation of hydrates $\left(\mathrm{CH}_{3} \mathrm{COO}^{-}\left(\mathrm{H}_{2} \mathrm{O}\right)_{\mathrm{n}=0,1,2 . .}\right)$ which reduces the signal on the mass peak of the unhydrated product ion and as a result, the signal-to-noise ratio $(\mathrm{S} / \mathrm{N})$. To minimize this effect, LQMS (linear quadrupole mass spectrometer) systems are often employed together with a collision dissociation chamber (CDC) in which hydrated ions undergo de-hydration before the ions enter the quadrupole. Inside the ion trap, ions are efficiently de-hydrated through collisions with the damping gas helium (see Sect. 2.3). Therefore, apart from measurements in the humid boundary layer, essentially only the unhydrated product ion is present in the mass spectra.

The thermal decomposition products of other PAN homologues (e.g. PPN and MPAN) react in the same way with $\mathrm{I}^{-}$, so these can be detected simultaneously at the corresponding mass peaks at $73\left(\mathrm{CH}_{3} \mathrm{CH}_{2} \mathrm{COO}^{-}\right)$or $85\left(\mathrm{CH}_{3} \mathrm{CCH}_{2} \mathrm{COO}^{-}\right)$amu. The sensitivity for a series of PAN homologues has been found to be similar within the family (Slusher et al., 2004; Turnipseed et al., 2006). The only exception is MPAN, for which consistent across a number of recent studies, a lower sensitivity by a factor of $\sim 4$ is observed (Slusher et al., 2004; Flocke et al., 2005a; LaFranchi et al., 2009), probably due to more complex processes in the thermal decomposition region (Zheng et al., 2011).

\subsection{Ion trap mass spectrometer (ITMS)}

The ion trap mass spectrometer (ITMS) was already deployed successfully on the Falcon for the measurement of
$\mathrm{SO}_{2}$ (Speidel et al., 2007; Fiedler et al., 2009) as well as for ground-based measurements of $\mathrm{OH}$ and $\mathrm{H}_{2} \mathrm{SO}_{4}$ (Fiedler et al., 2005; Aufmhoff et al., 2011).

The ITMS comprises the ion optics, the ion trap chamber and the detection unit. The manifold consists of two pumping stages: The first octapole region (octapoles are octagonal arrays of cylindrical rods) is evacuated down to $10^{-3} \mathrm{hPa}$ whereas the second octapole region, the trap chamber and the detection unit is operated at $3 \times 10^{-5} \mathrm{hPa}$. Pumping is carried out by means of a turbo-molecular pump (Balzers Pfeiffer TMH 260/130) backed-up by a membrane pump (Vacuubrand, MZ D4).

After entering the ITMS through the inlet orifice (diameter: $0.2 \mathrm{~mm}$, electrical potential $\sim+0.5 \mathrm{~V}$ ), located at the centre of a circular front electrode, the ions are guided into the quadrupole ion trap with the aid of the two octapoles and one inter-octapole lens. They are focused towards the entrance endcap electrode by means of a radio frequency (RF) voltage $(2.45 \mathrm{MHz}, 400 \mathrm{~V}$ zero to peak) and DC offset voltage $\sim+2 \mathrm{~V}$ and $\sim+6 \mathrm{~V}$ applied to the octapoles 1 and 2 , respectively. The sign of the potentials is opposite to the charge of the measured ions. The injection of the ions into the trap chamber is periodic, controlled by the inter-octapole lens which works as an electronic gate. For a short time period, the injection or trapping time, an attractive potential is applied to the gate drawing the ions into the second octapole region.

The trap chamber consists of a ring electrode and two hyperbolic electrodes which serve as entrance and exit endcaps. Both endcap electrodes have a small hole in their centres to permit the passage of ions into and out of the ion trap. A DC voltage is applied $(\sim+10 \mathrm{~V})$ to draw ions in from the ion optics. Helium is added with a flow of $\sim 1 \mathrm{sccm} / \mathrm{min}$ and serves as a collision gas to facilitate storage of injected ions ("kinetic cooling"). By means of an AC voltage of constant frequency $(0.76 \mathrm{MHz})$ and variable amplitude $(0$ to $8500 \mathrm{~V})$ applied to the ring electrode, a three-dimensional quadrupole field is established within the trap. This oscillating field drives ionic motion in both axial (toward the endcaps) and radial (toward the ring electrode) directions. The damping gas $\mathrm{He}$ concentrates the ions closer to the centre of the trap chamber increasing both trapping efficiency and mass resolution. Additionally, collisions between the injected ions and the He atoms induce CID (collision induced dissociation) of weakly bounded clusters, mainly associated water clusters, e.g. Kiendler et al. (2000). The latter effect simplifies the mass spectra obtained and increases the $\mathrm{S} / \mathrm{N}$ ratio.

The mass scan is performed during the ion read-out process by changing the RF potential (scan-rate $=5500 \mathrm{amu} / \mathrm{s}$ ). The RF amplitude is ramped up at a constant rate which increases the amplitude of the trajectories of the trapped ions, the "mass selective instability mode" (Stafford et al., 1984). The ions become destabilized in the axial direction and are ejected one after another through the second endcap electrode, starting with low $\mathrm{m} / \mathrm{z}$ ratios. The exit lens (at 
ground potential) focuses the ions towards a conversion dynode, which is located off-axis at a right angle to the ion beam and generates secondary electrons by ion impact. Thereafter, the electrons are amplified by an electron multiplier and converted into an electric current (15 channels/mass). The current is digitized by an analogue-to-digital converter and finally software-processed.

With the help of a software, all voltages of the ion optics and the trap chamber can be tuned in order to optimize the ion current and thus improve the detection sensitivity of the ions with the desired $\mathrm{m} / \mathrm{z}$ ratio. The optimized parameters are stored in a "Tune-File". The system allows software-averaging over the sum of several single mass spectra obtained (so-called micro-scans) to one macro-scan, which may increase the signal-to-noise $(\mathrm{S} / \mathrm{N})$ ratio considerably (see Sect. 3.1). The micro-scan time comprises the time for the injection of ions (trapping time), the time the ions are ejected for the mass scan (read-out time, dependent on the size of the chosen mass range) and several delay times, e.g. for the adjustment of the different voltages. The final time resolution is then given by the micro-scan time multiplied by the selected number of micro-scans.

It is also possible to run the ITMS in the automatic gain control mode (AGC). In this case, a short pre-scan is performed (duration of about $0.2 \mathrm{~ms}$ ) to obtain the actual ion concentration which varies due to changing humidity and trace gas abundance. The system then automatically adjusts the appropriate injection time for the analytic scan, corresponding to the maximum number of ions allowed in the trap (MS target). This is important in order to avoid space-charge effects, which would result in a loss of mass resolution. The conversion of the mass spectra obtained into time-series for each single mass peak as well as further data processing is carried out with the help of a custom-written routine in a commercial software (IGOR Pro).

\subsection{Isotopic PAN calibration source (PCS)}

There are two different ways to perform in-flight calibration of CIMS instruments. One way is to add a certain, wellknown amount of the measured trace gas several times on each flight in order to obtain information on the instrument performance over time and in different kinds of air masses. The best alternative is to use an isotopically labelled standard. It has the same ion chemical behaviour within the measurement uncertainty of most MS systems, and provides calibration throughout the whole flight, because it does not interfere with the product ion of the measured atmospheric trace gas. However, there are some points worthy of attention: (1) The mass spectrometer needs a sufficient mass resolution to be able to separate the adjacent peaks which are often only one or two mass peaks apart. (2) One has to ensure that no interfering signals contribute either to the mass peak of the measured trace gas or to the mass peak of the isotopic standard (see Sect. 3.3). Also the instrumental background of both mass peaks has to be determined regularly. (3) The isotopic distribution of both standard and ambient air has to be considered.

PAN is thermally not stable at room temperature but can be produced in-situ with the help of a photochemical method (Warneck and Zerbach, 1992). For this, acetone $\left(\mathrm{C}_{3} \mathrm{H}_{6} \mathrm{O}\right.$, $200 \mu \mathrm{mol} \mathrm{mol}^{-1}, 50 \mathrm{sccm} / \mathrm{min}$ in synthetic air, Air Liquide) is photolyzed and the product $\mathrm{CH}_{3} \mathrm{CO}$ reacts with abundant oxygen hereby forming PA radicals $\left(\mathrm{CH}_{3} \mathrm{C}(\mathrm{O}) \mathrm{O}_{2}\right)$. These oxidize the precisely added nitric oxide ( $\mathrm{NO}, 3 \mu \mathrm{mol} \mathrm{mol}^{-1}$, $1-3 \mathrm{sccm} / \mathrm{min}$ in $\mathrm{N}_{2} 5.0$, Air Liquide) rapidly to $\mathrm{NO}_{2}$. Finally, PAN is formed via Reaction (R1).

In our photolytic PAN calibration source (PCS) the reactions take place in a temperature- and pressure-controlled reaction chamber $\left(V=200 \mathrm{~cm}^{3}, 15^{\circ} \mathrm{C}, 1100 \mathrm{hPa}\right)$ which is externally covered with an aluminium foil. A phosphorous coated pen-ray lamp (Jelight Corp.) located in the centre of the reaction vessel photolyzes acetone efficiently at wavelengths around $285 \mathrm{~nm}$, but does not significantly photolyze $\mathrm{NO}_{2}$ and PAN (Warneck and Zerbach, 1992; Flocke et al., 2005b).

The PCS was characterized in detail with the help of our $\mathrm{NO} / \mathrm{NO}_{2} / \mathrm{NO}_{\mathrm{y}}$ measurement system described elsewhere (Ziereis et al., 2004) and has a NO to PAN conversion efficiency of $92 \pm 5 \%$ with the remainder mainly in the form of $\mathrm{NO}_{2}$. These results are comparable with similar PAN sources described in the literature (Volz-Thomas et al., 2002; Flocke et al., 2005b).

For in-flight calibrations isotopically labelled acetone $\left({ }^{13} \mathrm{C}_{3} \mathrm{H}_{6} \mathrm{O}\right)$ is used (Flocke et al., 2005a): the resulting PAN calibration peak is then shifted from mass peak $59 \mathrm{amu}$ $\left({ }^{12} \mathrm{CH}_{3}^{12} \mathrm{COO}^{-}\right)$to mass peak $61 \mathrm{amu}\left({ }^{13} \mathrm{CH}_{3}^{13} \mathrm{COO}^{-}\right)$. However, the isotopic calibration gas may contribute to a minor extent also to the ambient mass peak (59 amu), depending on its isotopic purity. The same argument holds for the ambient air, which may produce a signal also on the calibration mass peak, depending on the terrestrial isotopic distribution. Hence, the isotopic compositions of standard and ambient air have to be considered in the calculation of the ambient PAN concentration. This is achieved with the help of constants $K_{i j}$, where $i$ represents the mass peaks $59 \mathrm{amu}(\mathrm{a}=$ ambient $)$ and $61 \mathrm{amu}$ ( $\mathrm{s}=$ standard) to which the corresponding air $j$ ( $\mathrm{a}=$ ambient, $\mathrm{s}=$ standard) contributes. The ambient PAN mixing ratio can then be calculated via (Bandy et al., 1993):

$C_{\mathrm{a}}=C_{\mathrm{s}} \cdot\left(\frac{K_{\mathrm{ss}} \cdot R-K_{\mathrm{as}}}{K_{\mathrm{aa}}-K_{\mathrm{sa}} \cdot R}\right)$.

Herein, $C_{\mathrm{s}}$ is the mole fraction of the added standard (diluted with the sample flow) and $R$ the ratio of the instrument background-corrected signals at mass peaks 59 to $61 \mathrm{amu}$. $K_{\text {aa }}$ and $K_{\text {sa }}$ are calculated with the help of the terrestrial abundances of ${ }^{12} \mathrm{C}(98.9 \%),{ }^{13} \mathrm{C}(1.1 \%),{ }^{16} \mathrm{O}(99.762 \%)$ and ${ }^{18} \mathrm{O}(0.2 \%)$ while contributions of less abundant isotopes $\left({ }^{17} \mathrm{O}\right.$ and $\left.{ }^{2} \mathrm{H}\right)$ can be neglected. Taking all the possible permutations into account, $K_{\mathrm{aa}}$ and $K_{\mathrm{sa}}$ are calculated to 0.9731 


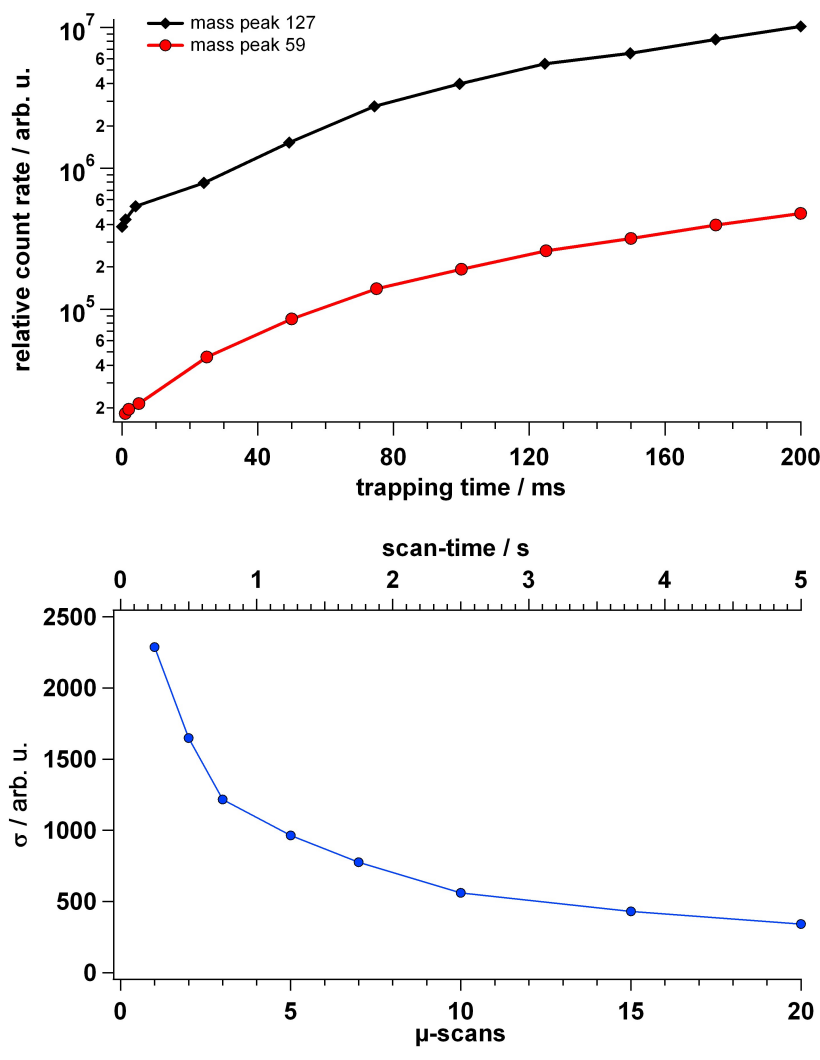

Fig. 2. Ion signals at mass peaks 59 and 127 amu versus the trapping time (upper panel). The lower panel shows the standard deviation at instrumental background conditions (BCU-mode) versus the number of micro-scans (trapping time: $100 \mathrm{~ms}$ ). The corresponding scan-time is plotted on the top axis.

and $2.1 \times 10^{-3}$, respectively. The latter only becomes important for a high ratio $R$, hence for ambient PAN mixing ratios much higher than the added standard PAN mole fraction. $K_{\mathrm{ss}}$ and $K_{\text {as }}$ have to be determined experimentally in the laboratory, since each calibration gas may have a different isotopic composition. We found that the standard used for the POLARCAT-GRACE campaign (Air Liquide) was isotopically pure within our measurement uncertainty, i.e. the constants for this standard were set to $K_{\mathrm{ss}}=1$ and $K_{\mathrm{as}}=0$, respectively. During airborne measurements, the isotopic calibration gas $\left(52 \mathrm{sccm} / \mathrm{min}, 106.2 \mathrm{nmol} \mathrm{mol}^{-1}\right.$ PAN) was added shortly after the air inlet to the sample gas flow (see Fig. 1).

\section{Instrument characteristics}

\subsection{Ion trap settings}

A better time resolution generally leads to a higher detection limit and vice versa, thus one has to find a reasonable compromise for the required application. The parameters described in Sect. 2.3, i.e. the trapping time, the maximum number of ions allowed in the trap (MS target) and the number of micro-scans have been optimized in the preface of the campaign for a high time resolution and a sufficiently low detection limit.

Higher trapping times generally lead to higher ion signals, thus greater sensitivity. The upper panel of Fig. 2 shows as an example the signals at mass peaks $127 \mathrm{amu}$ and $59 \mathrm{amu}$ versus trapping times between 1 and $200 \mathrm{~ms}$. The mass peak at $127 \mathrm{amu}$ belongs to the reagent ion $\mathrm{I}^{-}$and the mass peak at 59 amu to the product ion $\mathrm{CH}_{3} \mathrm{COO}^{-}$(see Reaction $\mathrm{R} 2$ and Fig. 3). The CIMS-method relies on ion abundance ratios and not absolute ion concentrations or absolute ion count rates. As described in Sect. 2.3, ion currents are measured using a conversion dynode, followed by a multiplier and an electrometer. The analogue ion current output of the electrometer is then digitalized and converted to a frequency, which is proportional to the rate of ion impingements on the conversion dynode. However, this frequency represents not the absolute rate of ion impingements (ion count rate). The dimension of this frequency is per second, but this frequency should not be termed ion count rate to avoid misunderstandings. Therefore, in the following we will report all ion signal outputs as "relative count rate/arb. u.".

During this experiment, a constant PAN concentration was established in the FR. Trapping times longer than $\sim 200 \mathrm{~ms}$ (corresponding to $\sim 1 \times 10^{8}$ ions) resulted in a peak shape degradation due to overloading of the trap. For the GRACE campaign the MS target was, therefore, set to $5 \times 10^{7}$ in order to prevent a loss of mass resolution, resulting in trapping times of $\sim 60-80 \mathrm{~ms}$ on average. A maximum trapping time of $100 \mathrm{~ms}$ was chosen in order to keep the time resolution reasonable, hence, at low ion concentrations the trap was closed after $100 \mathrm{~ms}$.

The standard deviation $\sigma$ at instrumental background conditions (i.e. measuring PAN-free air) is a very important parameter since the detection limit is a linear function of it. As mentioned before, the system software allows the averaging over several single mass spectra ( $\mu$-scans). For constant trapping times, the standard deviation decreases strongly with a higher number of $\mu$-scans, as illustrated in the lower panel of Fig. 2. It shows as an example $\sigma$ in dependency of the number of micro-scans, the trapping time was held constant at $100 \mathrm{~ms}$. For this laboratory experiment, the sample gas containing a PAN mixing ratio of $\sim 1 \mathrm{nmol} \mathrm{mol}{ }^{-1}$ was drawn through the BCU before it entered the ITMS. The top axis gives the corresponding scan-time and hence, the obtainable time resolution. Please note that the read-out time has to be accounted for each micro-scan (see Sect. 2.3). For the GRACE measurements we used 10 micro-scans which turned out to be a good compromise between detection limit and time resolution. 

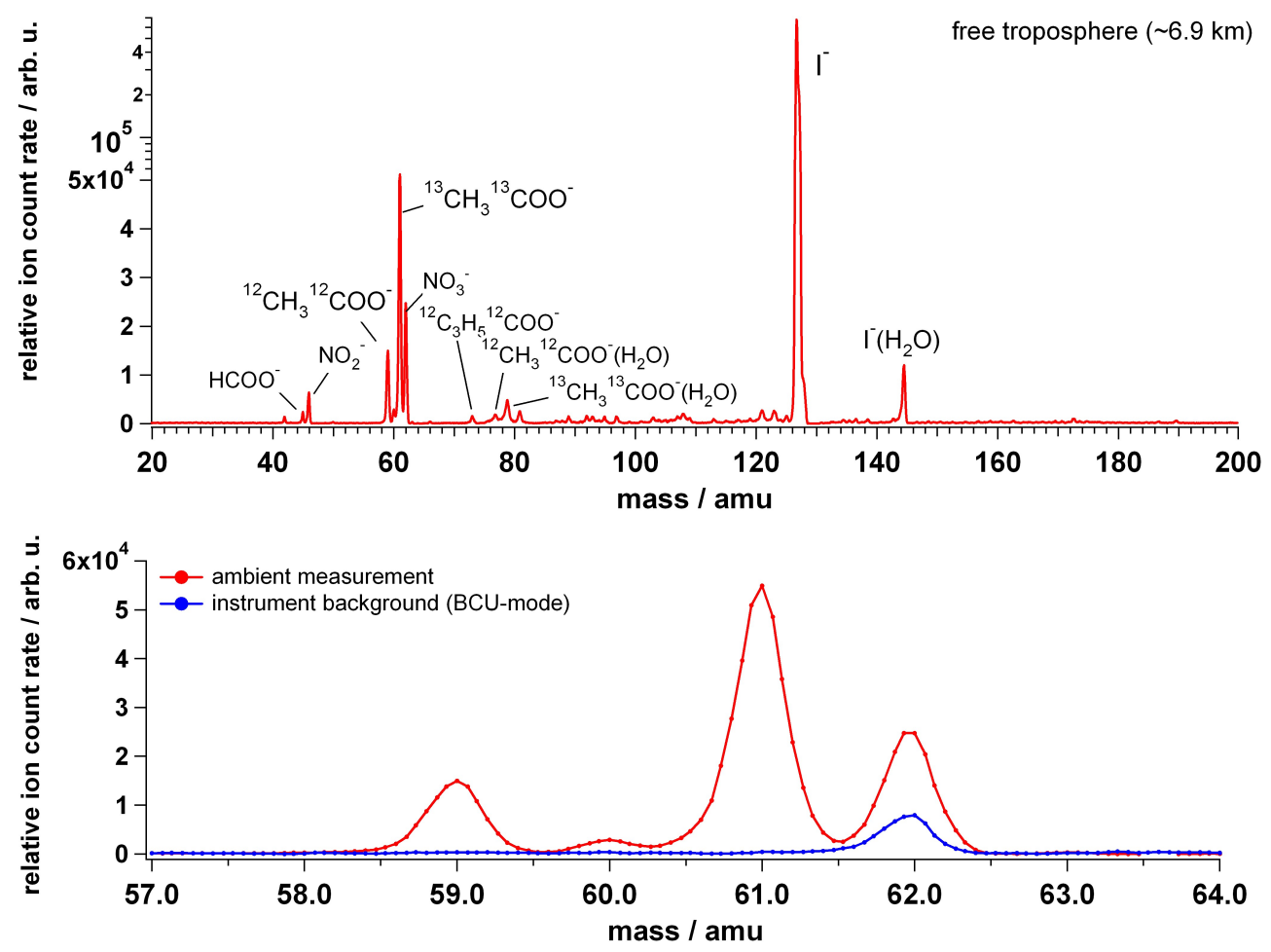

Fig. 3. Representative mass spectrum obtained during atmospheric measurements in the upper troposphere at $6.9 \mathrm{~km}$ (upper panel). Note the logarithmic scale above $5 \times 10^{4}$. The main peaks correspond to the reagent ions $\mathrm{I}^{-}(127 \mathrm{amu})$, the isotopic calibration ions ${ }^{13} \mathrm{CH}_{3}^{13} \mathrm{COO}^{-}(61 \mathrm{amu})$, the impurity ions $\mathrm{NO}_{3}^{-}(62 \mathrm{amu})$ and finally to ${ }^{12} \mathrm{CH}_{3}^{12} \mathrm{COO}^{-}$(59 amu), reflecting the ambient PAN mixing ratio $\left(281 \mathrm{pmol} \mathrm{mol}^{-1}\right)$. A blow-up of the mass-segment for 57 to $64 \mathrm{amu}$ is shown in the lower panel, together with a spectrum obtained during a background determination (BCU-mode). For more details see text.

\subsection{Flow reactor conditions}

Several parameters such as, for example, ion residence time, source gas flow or flow reactor pressure influence the yield of product ions of a certain ion-molecule reaction. Some of these are, however, considerably constrained for airborne measurements. Space, weight and gas supply limitations, as well as low ambient pressure at high altitudes, and finally the need for a high time resolution, are the main difficulties. With the given limitations we found the best results for our set-up at a FR pressure of $70 \mathrm{hPa}$ (limited by the lowest ambient pressure), a sample gas flow of $5.2 \mathrm{sL} / \mathrm{min}$ (limited by our flow reactor pump) and a $\mathrm{N}_{2}$ carrier source gas flow of $2.2 \mathrm{sL} / \mathrm{min}$ (limited by the available gas on board). The ion residence time in the FR for this set-up is $\sim 60 \mathrm{~ms}$.

\subsection{Cross sensitivities}

$\mathrm{I}^{-}$-ions are known to react very selectively with peroxyacyl radicals and are un-reactive with most other abundant trace gases as for example $\mathrm{HNO}_{3}, \mathrm{O}_{3}$ and $\mathrm{NO}_{2}$ (Huey et al., 1995). Slusher et al. (2004) found no cross sensitivities for typical ambient levels of acetone and acetic acid. They also discussed negative interferences due to reactions taking place in the heated inlet (TDR), which are titration of the PA radicals with $\mathrm{NO}$, recombination with $\mathrm{NO}_{2}$, and radical-radical self reactions. The influence of these reactions can be minimized by enhancing the flow through and temperature of the TDR. It is worth noting that these reactions are fully accounted for if an on-line isotopic calibration is used.

However, isotopic calibrated systems may suffer if other trace gases produce a signal only at one of the two mass peaks used for the calculation of the measured species, or a signal to a different extent on these. For the ion-molecule reaction described here, acetic acid $\left(\mathrm{CH}_{3} \mathrm{COOH}\right)$ may complicate the measurement due to an isotope exchange reaction (Zheng et al., 2011). Ambient $\mathrm{CH}_{3} \mathrm{COOH}$ may react with ${ }^{13} \mathrm{CH}_{3}^{13} \mathrm{COO}^{-}$which is produced by the isotopically labelled PAN :

$$
\begin{aligned}
& { }^{13} \mathrm{CH}_{3}^{13} \mathrm{COO}^{-}+{ }^{12} \mathrm{CH}_{3}^{12} \mathrm{COOH} \rightarrow \\
& { }^{13} \mathrm{CH}_{3}^{13} \mathrm{COOH}+{ }^{12} \mathrm{CH}_{3}^{12} \mathrm{COO}^{-} .
\end{aligned}
$$

Reaction (R3) shows that one ${ }^{12} \mathrm{CH}_{3}^{12} \mathrm{COO}^{-}$(product of ambient PAN) per acetic acid molecule is formed while one ${ }^{13} \mathrm{CH}_{3}^{13} \mathrm{COO}^{-}$(product of the PAN standard) is consumed. As a result the mass peak at $59 \mathrm{amu}$ increases while the mass 
peak at 61 amu decreases, which finally even doubles the effect on the calculated PAN concentration. Obviously, this cross-sensitivity becomes more important at high isotopic standard concentrations (more ${ }^{13} \mathrm{CH}_{3}^{13} \mathrm{COO}^{-}$) as well as at longer ion residence times.

To test this influence on our POLARCAT-GRACE setup, we added $\mathrm{CH}_{3} \mathrm{COOH}$ with the help of a permeation source (VICI Metronics) at different concentrations up to several $\mathrm{nmol} \mathrm{mol}^{-1}$. For atmospheric acetic acid mixing ratios of $2 \mathrm{nmol} \mathrm{mol}^{-1}$, we calculated an influence of less than $2 \%$. Typical ambient levels of $\mathrm{CH}_{3} \mathrm{COOH}$ are $1 \mathrm{nmol} \mathrm{mol}^{-1}$ or lower (Reiner et al., 1999; Finlayson-Pitts and Pitts, 2000), so we assume that this cross-sensitivity can be neglected for the GRACE measurements. This estimation is supported by one of our two different instrumental background determinations: the isotopically labelled standard was switched off several times on each flight (noILS-mode, see Sect. 4.2). The mass peak 59 amu never showed a decrease, as it would be expected for a significant cross-sensitivity to $\mathrm{CH}_{3} \mathrm{COOH}$.

We also tested cross-sensitivities for other abundant trace gases which were added by using calibration gases (Air Liquide) or permeation devices (VICI Metronics). The influence of $\mathrm{HNO}_{3}, \mathrm{NO}, \mathrm{O}_{3}, \mathrm{NO}_{2}, \mathrm{HCl}$ and $\mathrm{SO}_{2}$ was determined at levels typical for tropospheric/stratospheric air masses. Some of these gases gave a (small) signal on different mass peaks. For example $\mathrm{NO}_{2}$ contributed to mass peak $62\left(\mathrm{NO}_{3}^{-}\right)$and $\mathrm{HCl}$ to mass peak $163\left(\mathrm{I}^{-} \mathrm{HCl}\right)$. The addition of $\mathrm{HNO}_{3}$ increased the signal at mass peak $190\left(\mathrm{I}^{-} \mathrm{HNO}_{3}\right)$ and also at mass peak 62 , but we found no cross sensitivities for the relevant mass peaks at 59 or $61 \mathrm{amu}$.

\subsection{Accuracy and detection limit}

The accuracy of FASTPEX is largely determined by the uncertainty of the isotopically labelled standard which itself is composed of several inaccuracies. These include the uncertainties of the nitrogen oxide calibration gas $( \pm 1 \%$, Air Liquide), the gas flows of $\mathrm{NO}$ and acetone regulated by commercially available mass flow controllers $( \pm 0.5 \%$, Wagner Mess- und Regeltechnik), the sample gas flow controlled by a PFA critical orifice calibrated with a DryCal (D2) $( \pm 2 \%)$, and finally of the uncertainty of the NO to PAN conversion efficiency of our custom-made photolytic PAN source, which is about $\pm 5 \%$ given by the accuracy of our $\mathrm{NO} / \mathrm{NO}_{2} / \mathrm{NO}_{\mathrm{y}}$-system. At PAN mixing ratios greater than $\sim 200 \mathrm{pmol} \mathrm{mol}^{-1}$, the accuracy of FASTPEX is estimated as $\pm 10 \%$. At lower PAN mixing ratios the uncertainty of the instrumental background becomes more dominant and is highly dependent on the chosen time resolution. For a time resolution of $2 \mathrm{~s}$, we calculate the overall uncertainty to \pm 30 and $\pm 20 \%$ at 50 and $100 \mathrm{pmol} \mathrm{mol}^{-1}$, respectively.

The detection limit is defined as the concentration corresponding to the $2 \sigma$ standard deviation at instrumental background conditions. At a time resolution of $2 \mathrm{~s}$ the $2 \sigma-$ detection limit is calculated as $25 \mathrm{pmol} \mathrm{mol}^{-1}$, but may be improved by increasing the number of $\mu$-scans (see Sect. 3.1).

\section{Atmospheric measurements}

FASTPEX was successfully deployed for the first time on the DLR Falcon in the framework of the POLARCATGRACE campaign between 30 June and 18 July 2008. Data were sampled during 16 local flights out of Kangerlussuaq (Greenland) and 2 transfer flights between Kangerlussuaq and Oberpfaffenhofen near Munich (Germany). One of the main objectives of the field campaign was to study the influence of boreal biomass burning plumes transported into the European Arctic and to determine the chemical processing and aerosol-ageing of the forest fire emissions during long-range transport. Scientific results of the POLARCATGRACE campaign will be discussed in more detail in a companion paper (Roiger et al., 2011). In the following section we mainly show mass spectra and raw data, discuss some characteristic properties of the ion trap mass spectrometer, and finally show some examples of the atmospheric PAN and PPN measurements.

\subsection{Atmospheric mass spectra}

A representative mass spectrum (averaged over 20 single spectra) is plotted in Fig. 3. The spectrum was obtained at an altitude of $6.9 \mathrm{~km}$ in the upper troposphere. Please note the logarithmic scale above $5 \times 10^{4}$. The by far largest mass peak is the reagent ion $\mathrm{I}^{-}$. Besides bare $\mathrm{I}^{-}$-ions, also some $\mathrm{I}^{-}\left(\mathrm{H}_{2} \mathrm{O}\right)$ at mass peak $145 \mathrm{amu}$ is present (ratio $\sim 70: 1$ ), but no $\mathrm{I}^{-}\left(\mathrm{H}_{2} \mathrm{O}\right)_{2}$. As intended, the collisional ion dehydration in the trap is very efficient. The second largest mass peak at $61 \mathrm{amu}$ is due to the isotopically labelled PAN calibration ion ${ }^{13} \mathrm{CH}_{3}^{13} \mathrm{COO}^{-}$, which corresponds to a PAN mole fraction of $1062 \mathrm{pmol} \mathrm{mol}^{-1}$. A trace of its hydrated form is also present $(79 \mathrm{amu})$. The third largest mass peak at $62 \mathrm{amu}$ is due to the impurity ion $\mathrm{NO}_{3}^{-}$, which may originate from ion-molecule reactions with $\mathrm{HNO}_{3}, \mathrm{NO}_{2}$ or $\mathrm{N}_{2} \mathrm{O}_{5}$. Next in abundance is the ambient $\mathrm{CH}_{3} \mathrm{COO}^{-}(59 \mathrm{amu})$, reflecting a PAN mole fraction of $281 \mathrm{pmol} \mathrm{mol}^{-1}$. Mass peak $73 \mathrm{amu}\left(\mathrm{C}_{2} \mathrm{H}_{5} \mathrm{COO}^{-}\right)$is equivalent to a PPN mole fraction of $36 \mathrm{pmol} \mathrm{mol}^{-1}$. Always present in the spectra are enhanced signals at mass peak 45 and $46 \mathrm{amu}$, probably due to $\mathrm{HCOO}^{-}$(Veres et al., 2008) and HONO (Roberts et al., 2010). A blow-up of the mass-segment for 57 to $64 \mathrm{amu}$ is given in the lower panel of Fig. 3. Additionally, an instrumental background spectrum is shown (BCU-mode). Herein, the signals at mass peak 59 and $61 \mathrm{amu}$ are close to zero and the ion intensity at mass peak $62 \mathrm{amu}$ has decreased but is still high.

A zoom into spectra obtained during measurements in the polluted boundary layer over Southern Germany (upper panel) and in the lowermost stratosphere (lower panel) is 

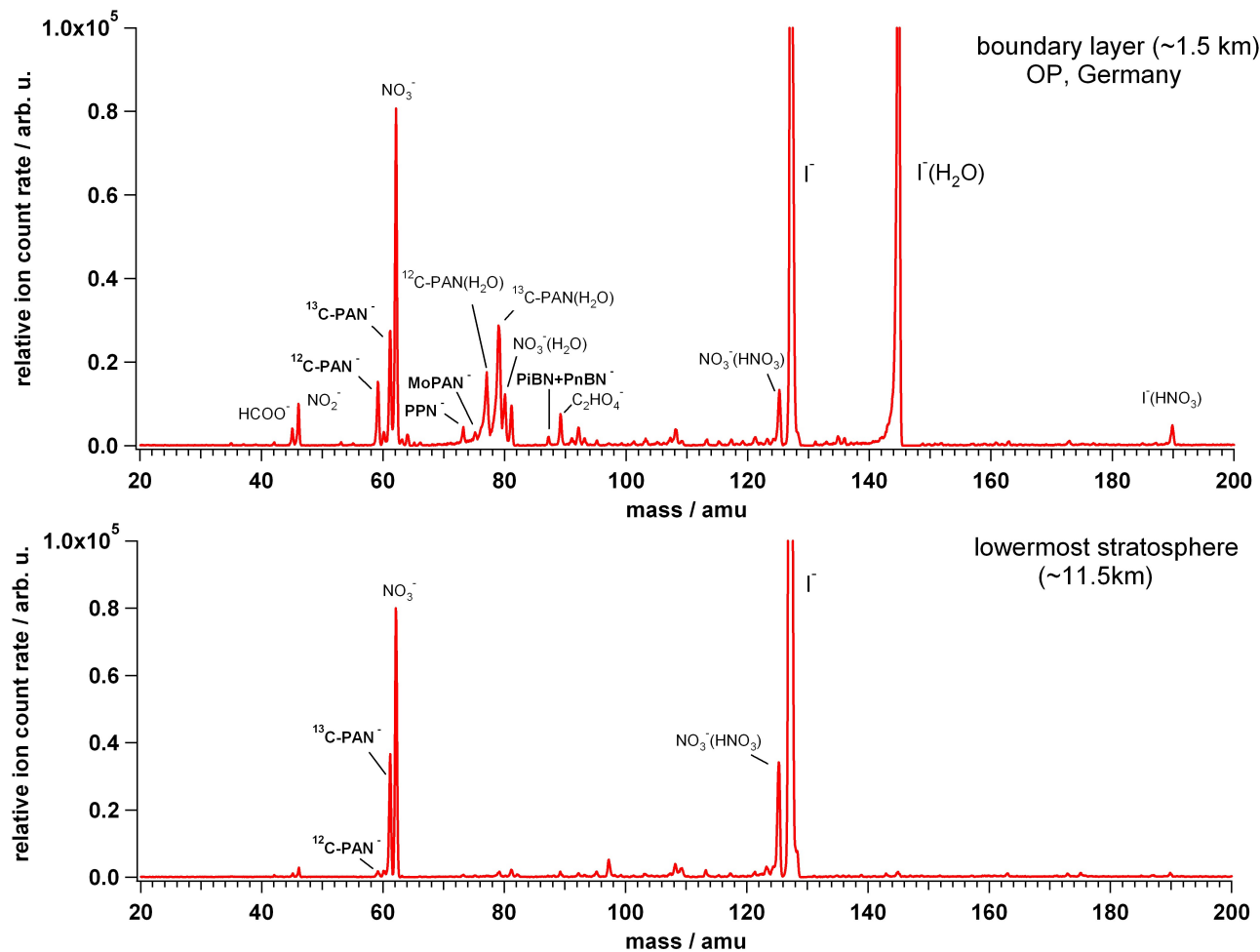

Fig. 4. Mass spectra obtained in the polluted boundary layer (BL) over Southern Germany (upper panel) and in the lowermost Arctic stratosphere (lower panel). The high humidity in the BL is reflected in the abundance of hydrated ions whereas the spectrum obtained in the lowermost stratosphere shows almost no hydrated forms. For more details see text.

given in Fig. 4 (each averaged over 20 single spectra). Due to the much higher humidity in the lower troposphere (altitude $1.5 \mathrm{~km}$ ), the ratios of the de-hydrated to hydrated ions are greatly reduced. The $\mathrm{I}^{-} / \mathrm{I}^{-}\left(\mathrm{H}_{2} \mathrm{O}\right)$ ratio is now only about $\sim 3: 1$ (cut in Fig. 4, upper panel). The abundance ratio of $\mathrm{CH}_{3} \mathrm{COO}^{-} / \mathrm{CH}_{3} \mathrm{COO}^{-}\left(\mathrm{H}_{2} \mathrm{O}\right)$ is close to 1 since $\mathrm{CH}_{3} \mathrm{COO}^{-}$ clusters stronger with water than $\mathrm{I}^{-}$(NIST, 2010). The measured PAN signal is equivalent to an ambient atmospheric PAN mole fraction of $648 \mathrm{pmol} \mathrm{mol}^{-1}$. It is worth noting that the isotopic calibration peak can still be used, because both ambient and standard ions experience the same water association and subsequently also the same dehydration within the ion trap. However, the PPN peak now sits on the rising edge of the ions corresponding to the hydrated forms of ambient and standard PAN ions (77 and $79 \mathrm{amu}$ ). As a result, the PPN background depends on water vapour mixing ratios (see Sect. 4.3.2).

The measurements in the polluted boundary layer over Germany are the only case in which we saw also potential signatures of other higher PAN homologues, namely at mass peaks 75 and $87 \mathrm{amu}$. These might correspond to $\mathrm{MoPAN}\left(\mathrm{CH}_{3} \mathrm{OC}(\mathrm{O}) \mathrm{OONO}_{2}\right)$ and the sum of PBNs $\left(\left(\mathrm{CH}_{3}\right)_{2} \mathrm{CHC}(\mathrm{O}) \mathrm{OONO}_{2}\right.$, peroxyisobutyryl nitrate and $\mathrm{CH}_{3}\left(\mathrm{CH}_{2}\right)_{2} \mathrm{C}(\mathrm{O}) \mathrm{OONO}_{2}$, peroxybutyryl nitrate), respectively (Slusher et al., 2004; Flocke et al., 2005a). At mass peak $85 \mathrm{amu}$ corresponding to MPAN
$\left(\mathrm{CH}_{3} \mathrm{CH}_{2} \mathrm{CC}(\mathrm{O}) \mathrm{O}_{2} \mathrm{NO}_{2}\right)$, which was often measured during earlier studies at mixing ratios of several 10 to $100 \mathrm{pmol} \mathrm{mol}^{-1}$ (Williams et al., 1997; Roberts et al., 2002, 2004), we observed no significant signal during any of the POLARCAT-GRACE flights. Actually we expected to see low MPAN mixing ratios since our measurement area was mainly influenced by aged pollution and not by local emissions. MPAN is, however, exclusively derived from isoprene chemistry, and has a short lifetime of only one or two days with respect to $\mathrm{OH}$ oxidation (Orlando et al., 2002). In the boundary layer, the higher $\mathrm{HNO}_{3}$ concentration is reflected in the enhanced signals at mass peaks $125\left(\mathrm{NO}_{3}^{-} \mathrm{HNO}_{3}\right)$ and $190 \mathrm{amu}\left(\mathrm{I}^{-} \mathrm{HNO}_{3}\right)$ and to some extent also at the impurity ion (62 amu) which is now more abundant than the calibration ion. The mass peak at $89 \mathrm{amu}$ might correspond to oxalic acid $\left(\mathrm{C}_{2} \mathrm{H}_{2} \mathrm{O}_{4}\right)$, the simplest di-carboxylic acid.

The lower panel of Fig. 4 shows a typical stratospheric spectrum. No more hydrated forms of the abundant ions are visible because of the low water vapour content. The PAN mixing ratio is here only $34 \mathrm{pmol} \mathrm{mol}^{-1}$. The higher $\mathrm{HNO}_{3}$ mixing ratio in the stratosphere is reflected at mass peak $125 \mathrm{amu}\left(\mathrm{NO}_{3}^{-} \mathrm{HNO}_{3}\right)$ but not at $190 \mathrm{amu}\left(\mathrm{I}^{-} \mathrm{HNO}_{3}\right)$, probably because the latter is formed primarily in a cluster exchange reaction with $\mathrm{I}^{-}\left(\mathrm{H}_{2} \mathrm{O}\right)$. 


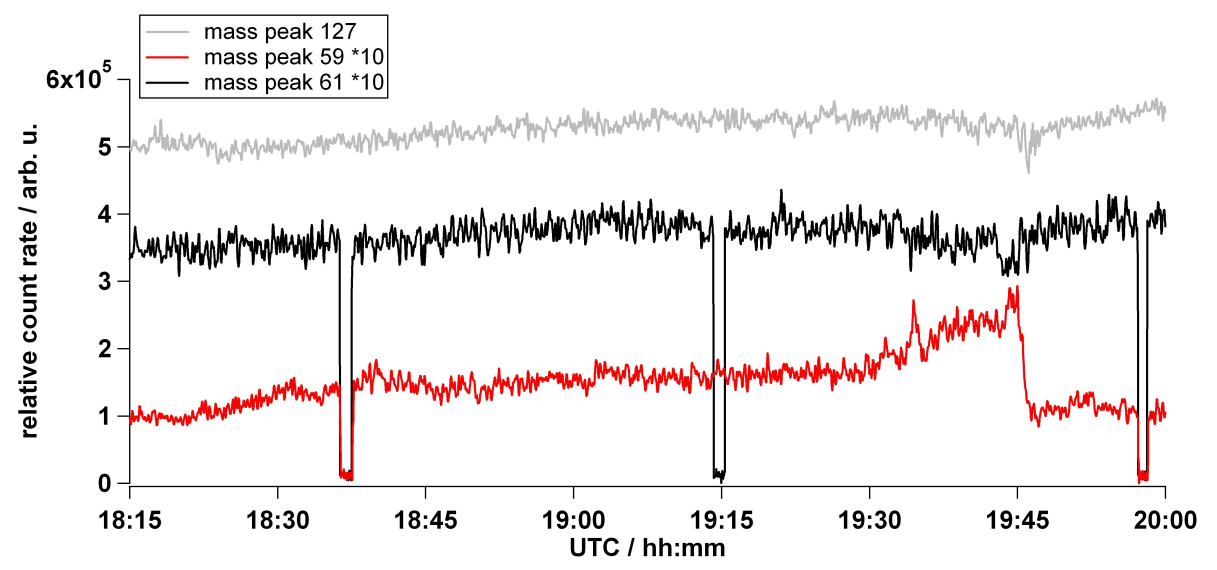

Fig. 5. Time series of the ion signals at mass peaks $59 \mathrm{amu}\left({ }^{12} \mathrm{CH}_{3}^{12} \mathrm{COO}^{-}\right), 61 \mathrm{amu}\left({ }^{13} \mathrm{CH}_{3}^{13} \mathrm{COO}^{-}\right)$and $127 \mathrm{amu}\left(\mathrm{I}^{-}\right)$for part of the flight on 9 July 2008. Mass peaks 59 and 61 amu are multiplied by a factor of 10. Three instrumental background determinations are shown, at about 18:37 UTC and 19:55 UTC (BCU-mode), and at 19:15 UTC (noILS-mode). See text for more details.

\subsection{In-flight calibration: isotopic standard and instrumental background}

A time sequence of mass peaks 59,61 and $127 \mathrm{amu}$ is shown in Fig. 5 as measured during part of the flight on 9 July 2008. While the calibration peak $\left({ }^{13} \mathrm{CH}_{3}^{13} \mathrm{COO}^{-}\right)$remains nearly constant, the mass peak 59 amu $\left({ }^{12} \mathrm{CH}_{3}^{12} \mathrm{COO}^{-}\right)$changes, reflecting atmospheric PAN variability. At about 19:45 UTC, the mass peak $59 \mathrm{amu}$ reaches a pronounced maximum, and hereafter decreases abruptly. Here, the Falcon encountered a pollution plume which was rich in PAN. The maximum of mass peak $59 \mathrm{amu}$ is accompanied by a weak minimum of mass peak $61 \mathrm{amu}$, which reflects losses of the highly reactive $\mathrm{CH}_{3} \mathrm{COO}^{-}$due to reactions with other trace gases having elevated concentrations in the biomass burning plume. On the other hand, the mass peak at $127 \mathrm{amu}$ remains relatively constant, since $\mathrm{I}^{-}$reacts almost exclusively with peroxyacyl radicals and is in great abundance. This example underlines the importance of the isotopic calibration: The ambient PAN product ion obviously will be lost in the same way, therefore the assumption of a constant sensitivity would in this case result in an underestimation of the ambient PAN mixing ratio.

Figure 5 also shows 3 background measurement phases at about 18:37, 19:15, and 19:55 UTC. The background signal on the mass peaks 59 and 61 amu was obtained several times on each flight by passing the sample gas first through the BCU (BCU-mode, 18:37 UTC and 19:55 UTC). Additionally, the isotopically labelled standard was switched off regularly in order to obtain a zero signal only at mass peak $61 \mathrm{amu}$ (noILS-mode, 19:15 UTC). We observed no significant changes in the background signals of both BCU- and noILS-mode over time, and for mass peak $61 \mathrm{amu}$ no difference between both background modes. No trends connected with polluted or stratospheric air masses were found, therefore we conclude that electronic noise variations but no chemical interferences were responsible for fluctuations of the instrumental background.

\subsection{Influence of water vapour}

\subsubsection{Sensitivity}

During all the POLARCAT-GRACE flights an isotopic PAN standard was added, producing a signal at mass peak $61 \mathrm{amu}$ $\left({ }^{13} \mathrm{CH}_{3}^{13} \mathrm{C}(\mathrm{O}) \mathrm{O}^{-}\right)$and, dependent on water vapour, also at mass peak $79 \mathrm{amu}\left({ }^{13} \mathrm{CH}_{3}^{13} \mathrm{C}(\mathrm{O}) \mathrm{O}^{-}\left(\mathrm{H}_{2} \mathrm{O}\right)\right)$. The mixing ratio of the PAN standard was kept constant, which allows us to discuss the sensitivity variations of the system in dependency on several parameters, as, for example, on ambient water vapour concentration. This is particularly interesting, since a water-vapour dependent sensitivity is reported for the PAN measurement using $\mathrm{I}^{-}$-chemistry, most probably due to a faster reaction of $\mathrm{CH}_{3} \mathrm{C}(\mathrm{O}) \mathrm{O}_{2}$ with $\mathrm{I}^{-}\left(\mathrm{H}_{2} \mathrm{O}\right)$ than with $\mathrm{I}^{-}$(Slusher et al., 2004; Flocke et al., 2005a). Figure 6 shows the ion signals at mass peak $61 \mathrm{amu}$ and the sum at mass peaks 61 and 79 amu in dependency on the ambient water vapour mixing ratio, as derived from all GRACE flights (note the logarithmic scale). Humidity was measured with the standard Falcon meteorological measurement system including a combination of three instruments: a commercial aircraft dew point hygrometer (GE 1011B, General Eastern), a slightly modified capacitive sensor (Humicap-H,Vaisala) and a Lyman-alpha absorption instrument (Buck Research, Boulder). The average signals (vertical markers show the standard deviation) are calculated for several bins of water vapour concentrations (indicated by the horizontal markers), the number of data points for each bin is given below.

Obviously, the signal of mass peak 61 is highest for ambient water vapour mixing ratios of about 200$1000 \mu \mathrm{mol} \mathrm{mol}^{-1}$. At lower humidities the ion intensity is less, probably due to the reported slower reaction with bare $\mathrm{I}^{-}$. However, the signal decreases with humidities greater 


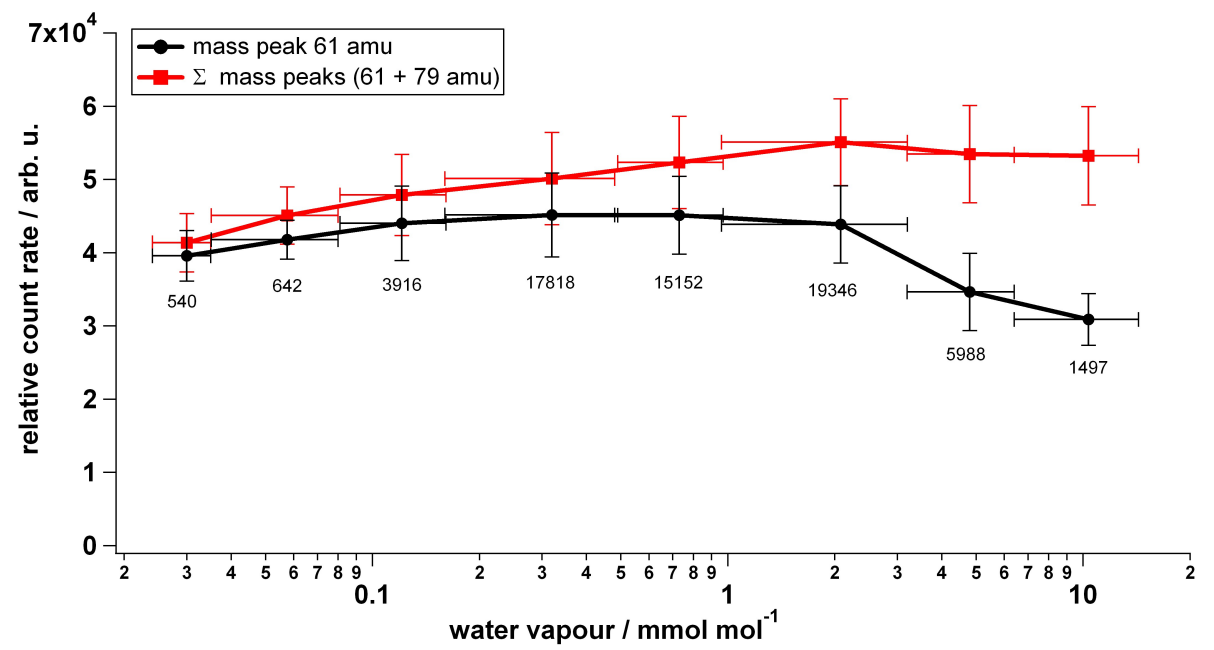

Fig. 6. Ion signals (avg) as measured for mass peaks $61 \mathrm{amu}\left({ }^{13} \mathrm{CH}_{3}^{13} \mathrm{COO}^{-}\right)$and for the sum of mass peaks 61 and 79 amu $\left({ }^{13} \mathrm{CH}_{3}^{13} \mathrm{COO}^{-}\left(\mathrm{H}_{2} \mathrm{O}\right)\right)$ for several bins of atmospheric humidity (indicated by horizontal markers). Vertical markers show the standard deviation for each bin, the number of data points is also given. At high humidities, the mass peak 61 amu decreases due to a shift to higher hydrates, whereas the sum of 61 and 79 amu remains relatively constant. At low humidity both signals decrease, mainly due to a slower reaction of $\mathrm{CH}_{3} \mathrm{COO}_{2}$ with bare $\mathrm{I}^{-}$compared to $\mathrm{I}^{-}\left(\mathrm{H}_{2} \mathrm{O}\right)$.

than $\sim 1000 \mu \mathrm{mol} \mathrm{mol}^{-1}$ even more strongly. This is a result of the higher abundance of hydrated forms of ions inside the flow reactor $\left({ }^{13} \mathrm{CH}_{3}^{13} \mathrm{C}(\mathrm{O}) \mathrm{O}^{-}\right)\left(\mathrm{H}_{2} \mathrm{O}\right)_{n=0,1,2, \ldots}$. These are not longer completely de-hydrated inside the trap, and therefore the signal is partly shifted to mass peak 79. This shift is confirmed by looking at the sum of both mass peaks, which shows, if any, only a small decrease at the highest water vapour mixing ratios. At the mass peak of the next hydrate (mass peak $97,{ }^{13} \mathrm{CH}_{3}^{13} \mathrm{C}(\mathrm{O}) \mathrm{O}^{-}\left(\mathrm{H}_{2} \mathrm{O}\right)_{2}$ ), we observed, also at the highest encountered humidities, no significant increase.

The observed water vapour dependency is accounted for by the on-line calibration. However, the detection limit is increased in the atmospheric boundary layer due to the lower sensitivity at the mass peak at 61 amu (by a maximum of $\sim 30 \%$ ).

\subsubsection{Instrumental background of PPN}

The instrumental PPN background has an interfering water vapour-dependent component at high ambient humidities ( $>1000 \mu \mathrm{mol} \mathrm{mol}^{-1}$ ), because the corresponding mass peak (73 amu) sits on the rising edge of the hydrated forms of the PAN product ions (see Sect. 4.1). In humid but clean air this artificial signal may become even higher than the ambient PPN signal. The in-flight background determinations (see Sect. 4.2) cannot be used for a correction, because the major responsible mass peaks at 77 and 79 amu (hydrated form of the ambient and the isotopic calibration ion) disappear here as well.

We tried to correct for the water vapour dependence by adopting the following approach: The mass peak at $73 \mathrm{amu}$ sits on the rising edge of mass peaks at higher $\mathrm{m} / \mathrm{z}$ ratios. Hence, the signals at mass peaks before and after the mass peak at 73 amu increase, too, approximately with a linear function towards higher mass peaks. We do not expect any atmospheric signal at the two mass peaks at 72 and $74 \mathrm{amu}$, which justifies taking the average of these two mass peaks as an instrumental background signal for mass peak $73 \mathrm{amu}$, easily calculable for each spectrum. The background values derived with this approach and their water vapour dependency were highly reproducible for all flights. For low-humidity conditions as prevalent in the upper troposphere/lowermost stratosphere, these calculated background signals show a good agreement with the values obtained with the help of the BCU-mode. Finally, we did some crosschecks for several cases per flight with the most accurate method: A linear curve fit to the bottom of the PPN peak, which we performed at different humidities and hence, different peak heights of mass peak 79 amu. The maximum discrepancy between these 3 different PPN instrumental background determinations was, translated into mixing ratios, $\sim 9 \mathrm{pmol} \mathrm{mol}^{-1}$. As a result, the PPN detection limit is likewise increased at high humidities $>1000 \mu \mathrm{mol} \mathrm{mol}^{-1}$.

\subsection{Time series of PAN and CO: flight on 7 July 2008}

To give an example of atmospheric PAN measurements, Fig. 7 shows a time series of PAN together with carbon monoxide (CO) for part of the flight on 7 July 2008 (13:45$15: 10$ UTC). CO was detected by a system using vacuum-UV fluorescence (Gerbig et al., 1999). The altitude of the Falcon is given at the $y$-axis on the left hand side. The top of Fig. 7 shows additionally a zoom into two parts of the timeseries. 


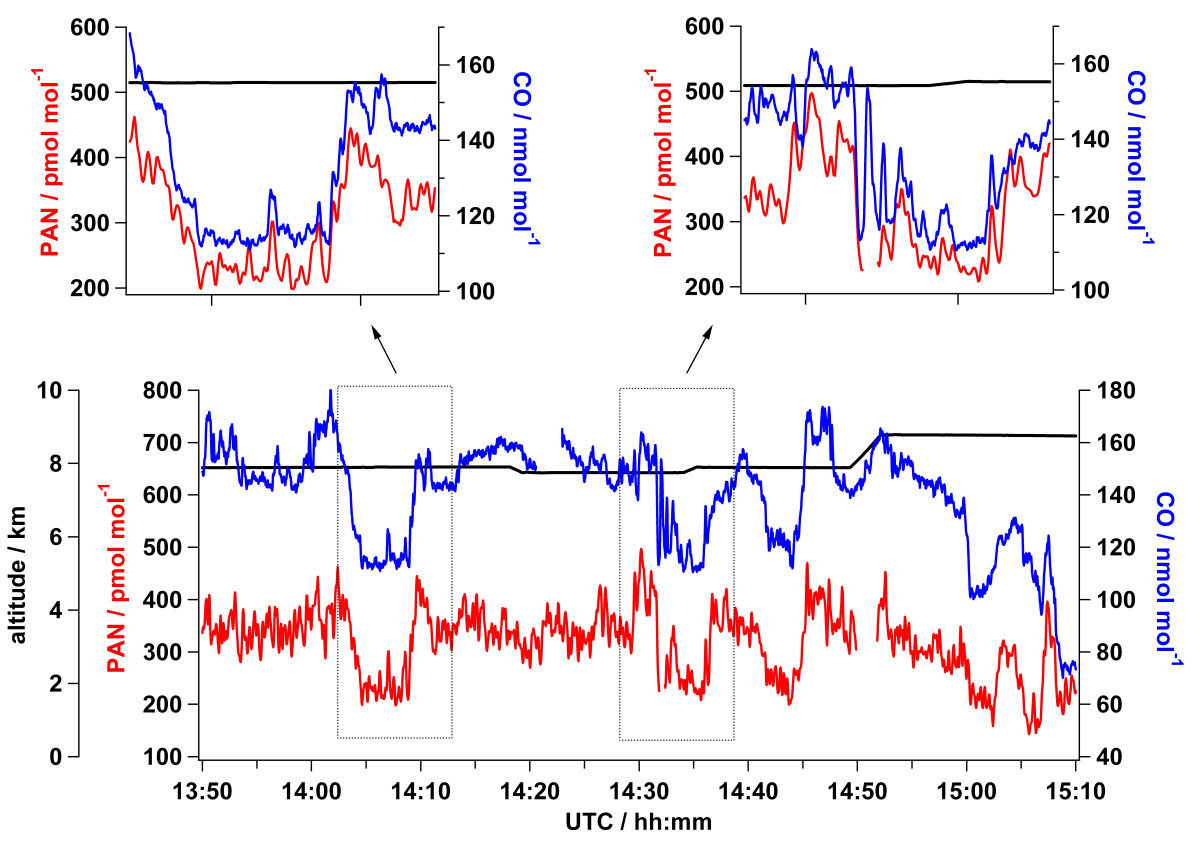

Fig. 7. Time series of PAN ( $2 \mathrm{~s})$ and CO (1 s) for part of the flight on 7 July (13:50-15:10 UTC). An aged Canadian biomass burning plume was intercepted several times at slightly different altitudes, as indicated by elevated PAN and CO concentrations $\left(\mathrm{PAN}>300 \mathrm{pmol} \mathrm{mol}^{-1}\right.$, $\mathrm{CO}>150 \mathrm{nmol} \mathrm{mol}^{-1}$ ). A blow-up for two parts of the time-series is shown at the top.

The Falcon was guided into a biomass burning plume originating from Saskatchewan, Canada. The plume extended over several hundreds of kilometres, and was intercepted several times at slightly different altitudes, as indicated by higher concentrations of both PAN and CO. CO is produced during incomplete combustion processes and has a relatively long life-time of several weeks in the free troposphere. This makes $\mathrm{CO}$ an excellent pollution tracer for combustion processes. PAN is expected to have elevated concentrations in biomass burning plumes because fires emit both precursor gases needed for PAN formation: VOCs and $\mathrm{NO}_{\mathrm{x}}$ (see Reaction R1). Alvarado et al. (2010) found, for example, rapid conversion of nitrogen oxides into PAN in boreal biomass burning plumes, with values of up to $40 \%$ in the first few hours after emission. The stability of PAN especially in the middle and upper troposphere keeps the PAN mixing ratio high in the fire plumes, also during periods of long-range transport.

Inside the plume, the CO mixing ratio was $\sim 150$ $180 \mathrm{nmol} \mathrm{mol}^{-1}$ compared to $\sim 120 \mathrm{nmol} \mathrm{mol}^{-1}$ outside of it. PAN mole fractions were on average about $350 \mathrm{pmol} \mathrm{mol}^{-1}$ when the Falcon sampled the biomass burning pollution, atmospheric background mixing ratios of PAN were $\sim 200 \mathrm{pmol} \mathrm{mol}^{-1}$. The two blow-ups in the upper part of Fig. 7 show that as expected, PAN and CO correlate very well, not only in gross, but also in fine structures.

\subsection{Vertical distribution of PAN}

Two vertical PAN profiles are presented in Fig. 8, measured during the descent to Longyearbyen, Spitsbergen $\left(78^{\circ} 13^{\prime} \mathrm{N}\right.$, $15^{\circ} 33^{\prime}$ E) on 15 July 2008 and to Oberpfaffenhofen, Germany $\left(48^{\circ} 4^{\prime} \mathrm{N}, 11^{\circ} 16^{\prime} \mathrm{E}\right)$, on 18 July 2008 , respectively. The most obvious difference between the two profiles is observed at low altitudes, inside the atmospheric boundary layer. Although PAN here has only a thermal lifetime in the range of a few hours, on-going emissions of PAN precursor gases at Oberpfaffenhofen (close to Munich, Germany) keep the PAN mixing ratio at $\sim 600 \mathrm{pmol} \mathrm{mol}^{-1}$. On the other hand, local sources of $\mathrm{NO}_{\mathrm{x}}$ and VOCs are missing over Spitsbergen, which is reflected in decreasing PAN mixing ratios at lower altitudes.

Interestingly, the PAN concentrations throughout the free troposphere are quite comparable for both profiles, with mixing ratios of $\sim 300 \mathrm{pmol} \mathrm{mol}^{-1}$ also in the Arctic free troposphere although local pollution sources can be excluded. The high PAN concentrations can be attributed to the significant influence of long-range transport of pollution onto the Arctic free troposphere, which is also apparent in other trace gases such as, for example, CO (Roiger et al., 2011).

In the uppermost troposphere/lowermost stratosphere (UTLS) we observed generally smaller PAN concentrations. This can be explained by a combination of missing PAN formation due to a lack of PAN precursor gases (VOCs) and the comparatively short photolysis lifetime of $\sim 40$ days at theses altitudes (Talukdar et al., 1995). 


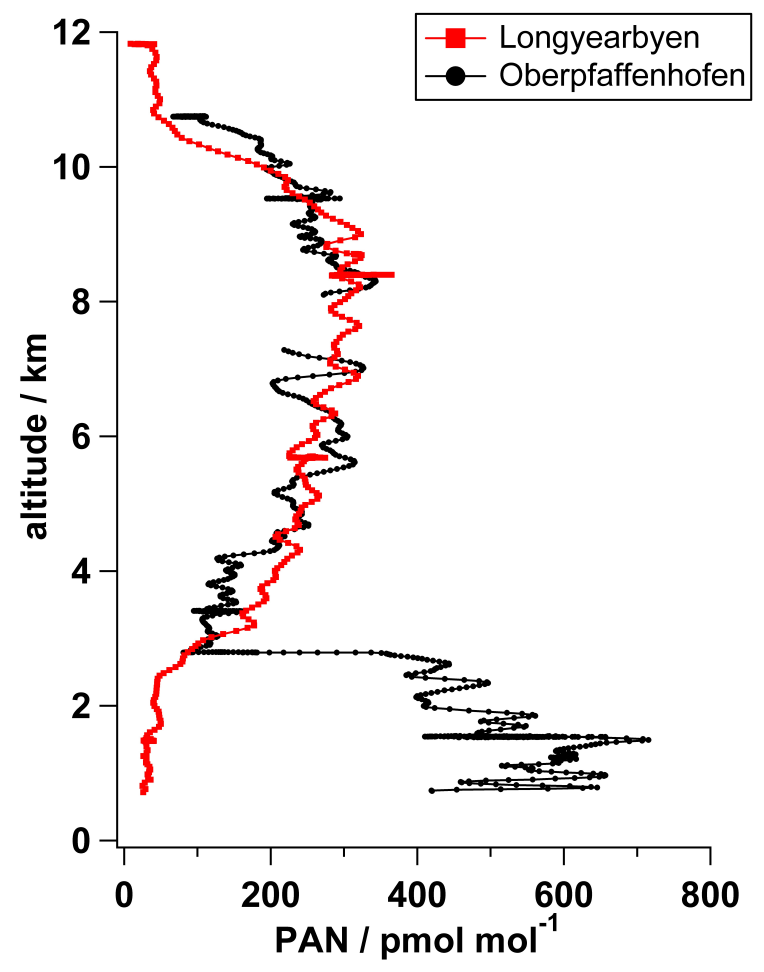

Fig. 8. Two vertical PAN profiles, sampled during the descent to Longyearbyen (15 July 2008) and to Oberpfaffenhofen (18 July 2008), respectively.

\subsection{PPN/PAN ratios}

Higher homologues of PAN can be detected simultaneously with the $\mathrm{I}^{-}$chemistry. The second most abundant PANtype compound is PPN (peroxypropionyl nitrate): reported PPN/PAN ratios vary from less than $2 \%$ up to more than $25 \%$ (Roberts et al., 2002, 2004; Flocke et al., 2005a; Wolfe et al., 2007). No isotopic calibration was applied for higher homologues of PAN. However, the sensitivity for both PAN and PPN can be assumed to be identical (Slusher et al., 2004; Flocke et al., 2005a; LaFranchi et al., 2009). For the calculation of PPN, in Eq. (1) the signal at mass $59 \mathrm{amu}$ is replaced by the signal at mass peak 73 amu (for calculation of ratio $\mathrm{R})$. Due to the proximity of the two mass peaks $(\Delta m / z=12)$, the relative mass discrimination of the ion trap can be neglected. The constant $K_{\text {aa }}$ in this case is set to 0.9662 , as calculated from the terrestrial isotopic distribution, whereas the constant $K_{\text {as }}$ (contribution from ambient PPN on the PAN calibration peak) is negligible.

The derived PPN mole fractions were most of the time below $\sim 50 \mathrm{pmol} \mathrm{mol}^{-1}$, as illustrated in Fig. 9. The correlation plot of PPN versus PAN contains $10 \mathrm{~s}$ values for all POLARCAT-GRACE flights. The bulk of the data (black crosses) lies within 0.03 to 0.3 which is in the range of values observed before.

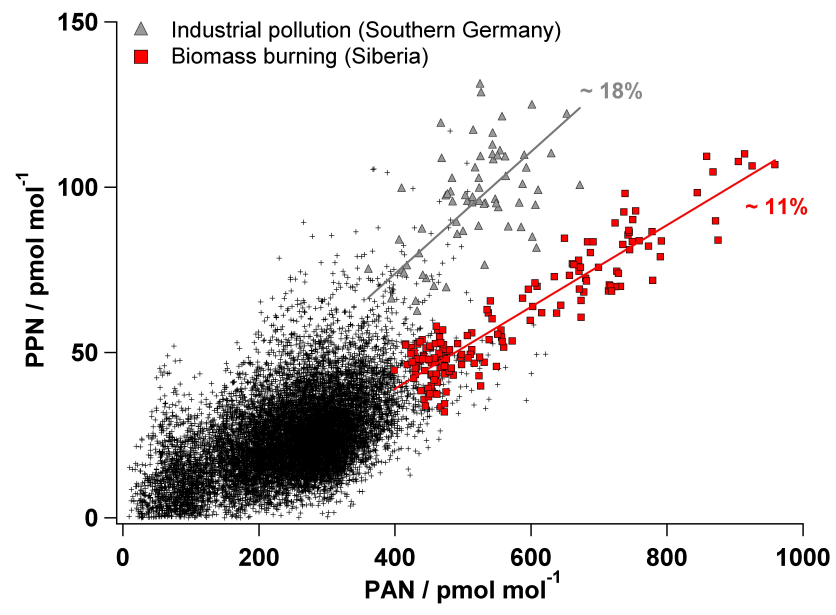

Fig. 9. PPN versus PAN for all POLARCAT-GRACE data $(10 \mathrm{~s})$ Dark grey triangles represent data from measurements in fresh anthropogenic pollution above southern Germany, red squares represent data obtained during the interception of an aged Siberian biomass burning plume. See text for more details.

For polluted situations we are able to determine precise PPN/PAN ratios. PPN mixing ratios measured during the descent to Oberpfaffenhofen on the 18 July 2008 (grey triangles in Fig. 9) belong to the highest observed values and are up to $\sim 130 \mathrm{pmol} \mathrm{mol}^{-1}$, the corresponding PPN/PAN ratio clusters around 0.18. Another main event was the interception of a Siberian biomass burning plume on 9 July, in which the highest PAN mixing ratios of almost $1 \mathrm{nmol} \mathrm{mol}^{-1}$ have been measured. The PPN mixing ratios in this plume were up to $\sim 110 \mathrm{pmol} \mathrm{mol}^{-1}$, which results in a significant lower PPN/PAN ratio of about 0.11 compared to the 0.18 measured in anthropogenic pollution. This observation is in agreement with previous measurements (Williams et al., 1997; Roberts et al., 1998, 2002). PPN is known to be formed mainly from anthropogenic hydrocarbons (e.g. propanal) whereas PAN derives from almost all non-methane hydrocarbon species, see e.g., Altshuller (1993).

\section{Summary and conclusions}

In this paper we have presented FASTPEX, a novel CIITMS (Chemical Ionization - Ion Trap Mass Spectrometer) instrument for fast and sensitive airborne measurements of PAN and PPN. FASTPEX was deployed for the first time on the DLR research aircraft Falcon during the POLARCATGRACE campaign in the summer of 2008, which was based in Kangerlussuaq, Greenland. A total of 16 local flights have been made in order to study the Arctic summer troposphere and lowermost stratosphere.

The parameters both of the ion trap mass spectrometer and of the ion-molecule reaction were optimized in the laboratory to reach a high time resolution of $\sim 2 \mathrm{~s}$ in combination 
with a low detection limit of $\sim 25 \mathrm{pmol} \mathrm{mol}^{-1}$. Pre- and post campaign laboratory tests showed that the PAN measurements did not suffer from cross-sensitivities to other trace gases. An isotopically labelled PAN standard using acetone with ${ }^{13} \mathrm{C}$ instead of ${ }^{12} \mathrm{C}$ was deployed, and for this reason the accuracy is estimated to be better than $10 \%$ for PAN mixing ratios greater than $200 \mathrm{pmol} \mathrm{mol}^{-1}$. The isotopic standard turned out to be especially important to account for the water vapour dependency of the PAN sensitivity, as well as for the high reactivity of the product ion which was especially observed in strongly polluted air masses. Two different kinds of instrumental background determinations were performed regularly during the flights, no trends in different kinds of air masses or any other drifts have been observed.

The constantly added isotopic standard was also used to study the water vapour dependency of our PAN measurements. The ion signal for PAN detection was highest in the free troposphere. In the humid boundary layer it was reduced due to a shift to hydrated product ions, and in the upper troposphere/lowermost stratosphere because of a lower rate constant of the used ion-molecule reaction.

PPN, a higher homologue of PAN, was measured simultaneously. The hydrated forms of the isotopic PAN calibration ions $\left(\mathrm{CH}_{3} \mathrm{COO}^{-}\left(\mathrm{H}_{2} \mathrm{O}\right)\right)$ increased the PPN background at high humidities (above $\sim 1000 \mu \mathrm{mol} \mathrm{mol}^{-1} \mathrm{H}_{2} \mathrm{O}$ ), which was accounted for with the help of an empirically derived correction.

Measured PAN median mixing ratios in the Arctic free troposphere were in the range of a few hundred $\mathrm{pmol} \mathrm{mol}^{-1}$ and showed generally a good correlation to carbon monoxide $\mathrm{CO}$, a combustion pollution tracer. In the lower Arctic troposphere and lowermost stratosphere smaller PAN mixing ratios were observed due to a combination of missing local sources of PAN precursor gases and efficient removal processes (thermolysis/photolysis). The measured PPN/PAN ratios were between $\sim 0.03$ and 0.3 , which is consistent with former observations. The PPN/PAN ratio of 0.11 found in an aged Siberian biomass burning plume was much lower than the ratio of 0.18 measured in fresh anthropogenic pollution over Southern Germany.

Future work will focus on certain aspects: (a) Calibration of PPN and higher homologues with the help of diffusion sources. (b) Water vapour dependency of sensitivity and PPN instrumental background (at humidities $>1000 \mu \mathrm{mol} \mathrm{mol}^{-1}$ ): we will optimize the de-clustering strength of the ion trap (e.g. by varying the helium flow and hence, the trap chamber pressure). Additionally, a lower isotopic PAN mixing ratio will be added during future ambient measurements. The latter also will reduce the possible cross-sensitivity to acetic acid.

Acknowledgements. This work was supported by the Deutsche Forschungsgemeinschaft (DFG) under SPP 1294 (SCHL1857/2-1) and PAK 348 (SCHL1857/3-1). The Falcon deployment for POLARCAT-GRACE was funded by DLR. We thank M. Scheibe and M. Lichtenstern for their help in acquiring this data set, and H. Ziereis for fruitful discussions about mass spectrometry. We also acknowledge the excellent support of the pilots and staff of the DLR Flight Department during the campaign. Frank Flocke (NCAR) is greatly acknowledged for his helpful comments on PAN synthesis and CIMS detection.

Edited by: D. Feist

\section{References}

Altshuller, A.: PANs in the atmosphere, J. Air Waste Manage., 43, 1221-1230, 1993.

Alvarado, M. J., Logan, J. A., Mao, J., Apel, E., Riemer, D., Blake, D., Cohen, R. C., Min, K.-E., Perring, A. E., Browne, E. C., Wooldridge, P. J., Diskin, G. S., Sachse, G. W., Fuelberg, H., Sessions, W. R., Harrigan, D. L., Huey, G., Liao, J., Case-Hanks, A., Jimenez, J. L., Cubison, M. J., Vay, S. A., Weinheimer, A. J., Knapp, D. J., Montzka, D. D., Flocke, F. M., Pollack, I. B., Wennberg, P. O., Kurten, A., Crounse, J., Clair, J. M. St., Wisthaler, A., Mikoviny, T., Yantosca, R. M., Carouge, C. C., and Le Sager, P.: Nitrogen oxides and PAN in plumes from boreal fires during ARCTAS-B and their impact on ozone: an integrated analysis of aircraft and satellite observations, Atmos. Chem. Phys., 10, 9739-9760, doi:10.5194/acp-10-9739-2010, 2010.

Arnold, F., Böhringer, H., and Henschen, G.: Composition measurements of stratospheric positive ions, Geophys. Res. Lett., 5, 653-655, 1978.

Aufmhoff, H., Hanke, M., Uecker, J., Schlager, H., and Arnold, F.: An Ion Trap CIMS instrument for combined measurements of atmospheric $\mathrm{OH}$ and $\mathrm{H} 2 \mathrm{SO} 4$ : First test measurements above and inside the planetary boundary layer, Int. J. Mass Spectrom., submitted, 2011.

Bandy, A. R., Thornton, D., and Driedger, A.: Airborne measurements of sulfur dioxide, dimethyl sulfide carbon disulfide, and carbonyl sulfide by isotope dilution gas chromatography/mass spectrometry, J. Geophys. Res., 98, 23423-23433, 1993.

de Gouw, J. A., Goldan, P. D., Warneke, C., Kuster, W. C., Roberts, J. M., Marchewka, M., Bertman, S. B., Pszenny, A. A. P., and Keene, W. C.: Validation of proton transfer reaction-mass spectrometry (PTR-MS) measurements of gas-phase organic compounds in the atmosphere during the New England Air Quality Study (NEAQS) in 2002, J. Geophys. Res., 108, ACH-1 to ACH11, 2003.

Edwards, G. D., Shepson, P. B., Grossenbacher, J. W., Wells, J. M., Patterson, G. E., Barket, D. J., Pressley, S., Karl, T., and Apel, E.: Development of an automated cylindrical ion trap mass spectrometer for the determination of atmospheric volatile organic compounds, Anal. Chem., 79, 5040-5050, 2007.

Fiedler, V., Dal Maso, M., Boy, M., Aufmhoff, H., Hoffmann, J., Schuck, T., Birmili, W., Hanke, M., Uecker, J., Arnold, F., and Kulmala, M.: The contribution of sulphuric acid to atmospheric particle formation and growth: a comparison between boundary layers in Northern and Central Europe, Atmos. Chem. Phys., 5, 1773-1785, doi:10.5194/acp-5-1773-2005, 2005.

Fiedler, V., Nau, R., Ludmann, S., Arnold, F., Schlager, H., and Stohl, A.: East Asian $\mathrm{SO}_{2}$ pollution plume over Europe - Part 1: Airborne trace gas measurements and source identification by 
particle dispersion model simulations, Atmos. Chem. Phys., 9, 4717-4728, doi:10.5194/acp-9-4717-2009, 2009.

Flocke, F., Swanson, A., Roberts, J., Pfister, G., Emmons, L., Lamarque, J.-F., Hess, P., Huey, G., Tanner, D., Ryerson, T., Neuman, A., Holloway, J., DeGouw, J., and Warneke, C.: Results from fast airborne measurements of PANs during the 2004 New England Air Quality Study, vol. A54C-03, AGU Fall Meeting, 2005a.

Flocke, F. M., Weinheimer, A. J., Swanson, A. L., Roberts, J. M., Schmitt, R., and Shertz, S.: On the measurements of PANs by gas chromatography and electron capture detection, J. Atmos. Chem., 52, 19-43, 2005b.

Gerbig, C., Schmitgen, S., Kley, D., Volz-Thomas, A., Dewey, K., and Haaks, D.: An improved fast-response vacuum-UV resonance fluorescence CO instrument, J. Geophys. Res., 104, 16991704, 1999.

Haagen-Smit, A. J.: Chemistry and physiology of Los Angeles smog, Ind. Eng. Chem., 44, 1342-1346, 1952.

Hanke, M., Umann, B., Uecker, J., Arnold, F., and Bunz, H.: Atmospheric measurements of gas-phase $\mathrm{HNO}_{3}$ and $\mathrm{SO}_{2}$ using chemical ionization mass spectrometry during the MINATROC field campaign 2000 on Monte Cimone, Atmos. Chem. Phys., 3, 417436, doi:10.5194/acp-3-417-2003, 2003.

Holzinger, R., Williams, J., Salisbury, G., Klüpfel, T., de Reus, M., Traub, M., Crutzen, P. J., and Lelieveld, J.: Oxygenated compounds in aged biomass burning plumes over the Eastern Mediterranean: evidence for strong secondary production of methanol and acetone, Atmos. Chem. Phys., 5, 39-46, doi:10.5194/acp-5-39-2005, 2005.

Huey, L. G.: Measurement of trace atmospheric species by chemical ionization mass spectrometry: Speciation of reactive nitrogen and future directions, Mass Spectrom. Rev., 26, 166-184, 2007.

Huey, L. G., Hanson, D. R., and Howard, C. J.: Reactions of $\mathrm{SF}_{6}^{-}$ and $\mathrm{I}^{-}$with atmospheric trace gases, J. Phys. Chem., 99, 50015008, 1995.

Jurkat, T., Voigt, C., Arnold, F., Schlager, H., Kleffmann, J. , Aufmhoff, H., Schaueble, D., Schaefer, M., and Schumann, U.: Measurements of HONO, NO and $\mathrm{SO} 2$ in aircraft exhaust plumes at cruise: Implications for hydroxyl radical induced oxidation, Geophys. Res. Lett., submitted, 2011.

Keim, C., Liu, G. Y., Blom, C. E., Fischer, H., Gulde, T., Höpfner, M., Piesch, C., Ravegnani, F., Roiger, A., Schlager, H., and Sitnikov, N.: Vertical profile of peroxyacetyl nitrate (PAN) from MIPAS-STR measurements over Brazil in February 2005 and its contribution to tropical UT NOy partitioning, Atmos. Chem. Phys., 8, 4891-4902, doi:10.5194/acp-8-4891-2008, 2008.

Kercher, J. P., Riedel, T. P., and Thornton, J. A.: Chlorine activation by $\mathrm{N}_{2} \mathrm{O}_{5}$ : simultaneous, in situ detection of $\mathrm{ClNO}_{2}$ and $\mathrm{N}_{2} \mathrm{O}_{5}$ by chemical ionization mass spectrometry, Atmos. Meas. Tech., 2, 193-204, doi:10.5194/amt-2-193-2009, 2009.

Kiendler, A. and Arnold, F.: Detection of gaseous oxygenated hydrocarbons in upper tropospheric and lower stratospheric aircraft borne experiments, Int. J. Mass Spectrom., 223-224, 733-741, 2003.

Kiendler, A., Aberle, S., and Arnold, F.: Positive ion chemistry in the exhaust plumes of an air craft jet engine and a burner: investigations with a quadrupole ion trap mass spectrometer, Atmos. Environ., 34, 4787-4793, 2000.

LaFranchi, B. W., Wolfe, G. M., Thornton, J. A., Harrold, S. A.,
Browne, E. C., Min, K. E., Wooldridge, P. J., Gilman, J. B., Kuster, W. C., Goldan, P. D., de Gouw, J. A., McKay, M., Goldstein, A. H., Ren, X., Mao, J., and Cohen, R. C.: Closing the peroxy acetyl nitrate budget: observations of acyl peroxy nitrates (PAN, PPN, and MPAN) during BEARPEX 2007, Atmos. Chem. Phys., 9, 7623-7641, doi:10.5194/acp-9-7623-2009, 2009.

Mielke, L. H., Erickson, D. E., McLuckey, S. A., Müller, M., Wisthaler, A., Hansel, A., and Shepson, P. B.: Development of a Proton-Transfer Reaction-Linear Ion Trap Mass Spectrometer for Quantitative Determination of Volatile Organic Compounds, Anal. Chem., 80, 8171-8177, 2008.

Moore, D. P. and Remedios, J. J.: Seasonality of Peroxyacetyl nitrate (PAN) in the upper troposphere and lower stratosphere using the MIPAS-E instrument, Atmos. Chem. Phys., 10, 6117-6128, doi:10.5194/acp-10-6117-2010, 2010.

Neuman, J. A., Gao, R. S., Schein, M. E., Ciciora, S. J., Holecek, J. C., Thompson, T. L., Winkler, R. H., McLaughlin, R. J., Northway, M. J., Richard, E. C., and Fahey, D. W.: A fast-response chemical ionization mass spectrometer for in situ measurements of $\mathrm{HNO}_{3}$ in the upper troposphere and lower stratosphere, Rev. Sci. Instrum., 71, 3886-3894, 2000.

Neuman, J. A., Parrish, D. D., Trainer, M., Ryerson, T. B., Holloway, J. S., Nowak, J. B., Swanson, A., Flocke, F., Roberts, J. M., Brown, S. S., Stark, H., Sommariva, R., Stohl, A., Peltier, R., Weber, R., Wollny, A. G., Sueper, D. T., Huebler, G., and Fehsenfeld, F. C.: Reactive nitrogen transport and photochemistry in urban plumes over the North Atlantic Ocean, J. Geophys. Res., 111, D23S54, 1-11, 2006.

NIST: NIST Standard Reference Database Number 69, edited by: Linstrom, P. J. and Mallard, W. G., National Institute of Standards and Technology, Gaithersburg MD, 20899, Bartmess, J., Negative Ion Energetics Data, 2010.

Nowak, J. B., Huey, L. G., Eisele, F. L., Tanner, D. J., Mauldin, R. L., I., Cantrell, C., Kosciuch, E., and Davis, D. D.: Chemical ionization mass spectrometry technique for detection of dimethylsulfoxide and ammonia, J. Geophys. Res., 107(D18), 4363, doi:10.1029/2001JD001058, 2002.

Orlando, J. J., Tyndall, G. S., Bertman, S. B., Chen, W., and Burkholder, J. B.: Rate coefficient for the reaction of $\mathrm{OH}$ with $\mathrm{CH}_{2}=\mathrm{C}\left(\mathrm{CH}_{3}\right) \mathrm{C}(\mathrm{O}) \mathrm{OONO}_{2}$ (MPAN), Atmos. Environ., 36, 1895-1900, 2002.

Reiner, T., Moehler, O., and Arnold, F.: Measurements of acetone, acetic acid, and formic acid in the northern midlatitude upper troposphere and lower stratosphere, J. Geophys. Res., 104, $13943-$ 13952, 1999.

Roberts, J. M., Williams, J., Baumann, K., Buhr, M. P., Goldan, P. D., Holloway, J., Huebler, G., Kuster, W. C., McKeen, S. A., Ryerson, T. B., Trainer, M., Williams, E. J., Fehsenfeld, F. C., Bertman, S. B., Nouaime, G., Seaver, C., Grodzinsky, G., Rodgers, M., and Young, V. L.: Measurements of PAN, PPN, and MPAN made during the 1994 and 1995 Nashville intensives of the southern oxidant study: implications for regional ozone production from biogenic hydrocarbons, J. Geophys. Res., 103, 22473-22490, 1998.

Roberts, J. M., Flocke, F., Stroud, C. A., Hereid, D., Williams, E., Fehsenfeld, F., Brune, W., Martinez, M., and Harder, H.: Ground-based measurements of peroxycarboxylic nitric anhydrides (PANs) during the 1999 southern oxidants study Nashville Intensive, J. Geophys. Res., 107(D21), 4554, 
doi:10.1029/2001JD000947, 2002.

Roberts, J. M., Flocke, F., Chen, G., de Gouw, J., Holloway, J. S., Huebler, G., Neuman, J. A., Jr., D. K. N., Nowak, J. B., Parrish, D. D., Ryerson, T. B., Sueper, D. T., Warneke, C., and Fehsenfeld, F. C.: Measurement of peroxycarboxylic nitric anhydrides (PANs) during the ITCT 2K2 aircraft intensive experiment, J. Geophys. Res., 109, 1-13, 2004.

Roberts, J. M., Marchewka, M., Bertman, S. B., Sommariva, R., Warneke, C., de Gouw, J., Kuster, W., Goldan, P., Williams, E., Lerner, B. M., Murphy, P., and Fehsenfeld, F. C.: Measurements of PANs during the New England air quality study 2002, J. Geophys. Res., 112, 1-14, 2007.

Roberts, J. M., Veres, P., Warneke, C., Neuman, J. A., Washenfelder, R. A., Brown, S. S., Baasandorj, M., Burkholder, J. B., Burling, I. R., Johnson, T. J., Yokelson, R. J., and de Gouw, J.: Measurement of HONO, HNCO, and other inorganic acids by negative-ion proton-transfer chemical-ionization mass spectrometry (NI-PT-CIMS): application to biomass burning emissions, Atmos. Meas. Tech., 3, 981-990, doi:10.5194/amt-3-981-2010, 2010.

Roiger, A., Schlager, H., Arnold, F., Scheibe, M., Aufmhoff, H., Stock, P., Lichtenstern, M., Burkhart, J., and Stohl, A.: Influence of biomass burning on the chemical composition of the summer arctic troposphere, Atmos. Chem. Phys. Discuss., in preparation, 2011.

Schroeder, D., Soldi-Lose, H., Semialjac, M., Loos, J., Schwarz, H., Eerdekens, G., and Arnold, F.: On gaseous $\mathrm{C}_{4} \mathrm{H}_{6} \mathrm{O}_{2}$ compounds in the atmosphere: new insights from collision experiments of the protonated molecules in the laboratory and on aircraft, Int. J. Mass Spectrom., 228, 35-47, 2003.

Singh, H. and Salas, L.: Methodology for the analysis of peroxyacetyl nitrate (PAN) in the unpolluted atmosphere, Atmos. Environ. A-Gen., 17, 1507-1516, 1983.

Singh, H. B., O’Hara, D., Herlth, D., Bradshaw, J. D., Sandholm, S. T., Gregory, G. L., Sachse, G. W., Blake, D. R., Crutzen, P. J., and Kanakidou, M. A.: Atmospheric measurements of peroxyacetyl nitrate and other organic nitrates at high latitudes: possible sources and sinks, J. Geophys. Res., 97, 16511-16522, 1992.

Slusher, D. L., Huey, L. G., Tanner, D. J., Flocke, F. M., and Roberts, J. M.: A thermal dissociation-chemical ionization mass spectrometry (TD-CIMS) technique for the simultaneous measurement of peroxyacyl nitrates and dinitrogen pentoxide, J. Geophys. Res., 109, 1-13, 2004.

Speidel, M., Nau, R., Arnold, F., Schlager, H., and Stohl, A.: Sulfur dioxide measurements in the lower, middle and upper troposphere: deployment of an aircraft-based chemical ionization mass spectrometer with permanent in-flight calibration, Atmos. Environ., 41, 2427-2437, 2007.

Stafford, G. C., Kelley, P., Syka, J., Reynolds, W., and Todd, J.: Recent improvements in and analytical applications of advanced ion trap technology, Int. J. Mass Spectrom., 60, 85-98, 1984.

Stephens, E. R., Hanst, P. L., Doerr, R. C., and Scott, W. E.: Reactions of nitrogen dioxide and organic compounds in air, Ind. Eng. Chem., 48, 1498-1504, 1956.

Talukdar, R. K., Burkholder, J. B., Schmoltner, A.-M., Roberts, J. M., Wilson, R. W., and Ravishankara, A. R.: Investigation of the loss processes for peroxyacetyl nitrate in the atmosphere: UV photolysis and reaction with OH, J. Geophys. Res., 100, 1416314174, 1995.
Thornton, D. C., Bandy, A. R., Tu, F. H., Blomquist, B. W., Mitchell, G. M., Nadler, W., and Lenschow, D. H.: Fast airborne sulfur dioxide measurements by atmospheric pressure ionization mass spectrometry (APIMS), J. Geophys. Res., 107(D22), 4632, doi:10.1029/2002JD002289, 2002.

Turnipseed, A. A., Huey, L. G., Nemitz, E., Stickel, R., Higgs, J., Tanner, D. J., Slusher, D. L., Sparks, J. P., Flocke, F., and Guenther, A.: Eddy covariance fluxes of peroxyacetyl nitrates (PANs) and NOy to a coniferous forest, J. Geophys. Res., 111, 1-17, 2006.

Veres, P., Roberts, J., Warneke, C., Welsh-Bona, D., Zahniserd, M., Herndond, S., Falla, R., and de Gouw, J.: Development of negative-ion proton-transfer chemical-ionization mass spectrometry (NI-PT-CIMS) for the measurement of gas-phase organic acids in the atmosphere, Int. J. Mass Spectrom., 1-3, 48-55, 2008.

Villalta, P. and Howard, C.: Direct kinetics study of the $\mathrm{CH}_{3} \mathrm{C}(\mathrm{O}) \mathrm{O}_{2}+\mathrm{NO}$ reaction using chemical ionization mass spectrometry, J. Phys. Chem., 100, 13624-13628, 1996.

Volz-Thomas, A., Xueref, I., and Schmitt, R.: An Automatic Gas Chromatograph and Calibration System for Ambient Measurements of PAN and PPN, Env. Sci. Pollut. Res., 4, 72-76, 2002.

Warneck, P. and Zerbach, T.: Synthesis of peroxyacetyl nitrate in air by acetone photolysis, Environ. Sci. Technol., 26, 74-79, 1992.

Warneke, C., de Gouw, J., Lovejoy, E., Murphy, P., Kuster, W., and Fall, R.: Development of proton-transfer ion trap-mass spectrometry: on-line detection and identification of volatile organic compounds in air, J. Am. Soc. Mass Spectr., 16, 1316-1324, 2005.

Williams, J., Roberts, J. M., Fehsenfeld, F. C., Bertman, S. B., Buhr, M. P., Goldan, P. D., Huebler, G., Kuster, W. C., Ryerson, T. B., Trainer, M., and Young, V.: Regional ozone from biogenic hydrocarbons deduced from airborne measurements of PAN, PPN, and MPAN, Geophys. Res. Lett., 24, 1099-1102, 1997.

Williams, J., Roberts, J. M., Bertman, S. B., Stroud, C. A., Fehsenfeld, F. C., Baumann, K., Buhr, M. P., Knapp, K., Murphy, P. C., Nowick, M., and Williams, E. J.: A method for the airborne measurement of PAN, PPN, and MPAN, J. Geophys. Res., 105, 28943-28960, 2000.

Wolfe, G. M., Thornton, J. A., McNeill, V. F., Jaffe, D. A., Reidmiller, D., Chand, D., Smith, J., Swartzendruber, P., Flocke, F., and Zheng, W.: Influence of trans-Pacific pollution transport on acyl peroxy nitrate abundances and speciation at Mount Bachelor Observatory during INTEX-B, Atmos. Chem. Phys., 7, 53095325, doi:10.5194/acp-7-5309-2007, 2007.

Zheng, W., Flocke, F., Swanson, A., Roberts, J., Tyndall, G., Orlando, J., Huey, G., and Tanner, D.: Calibration of a thermal decomposition chemical ionization mass spectrometer for the atmospheric measurement of peroxy acyl nitrates (PANs) in the atmosphere, Atmos. Chem. Phys., submitted, 2011.

Ziereis, H., Minikin, A., Schlager, H., Gayet, J. F., Auriol, F., Stock, P., Baehr, J., Petzold, A., Schumann, U., Weinheimer, A., Ridley, B., and Stroem, J.: Uptake of reactive nitrogen on cirrus cloud particles during INCA, Geophys. Res. Lett., 31, L05115, 1-4, 2004. 